\title{
Sexual selection and sperm quantity: meta-analyses of strategic ejaculation
}

\author{
Clint D. Kelly ${ }^{1,2 *}$ and Michael D. Jennions ${ }^{2}$ \\ ${ }^{1}$ Department of Ecology, Evolution EO Organismal Biology, Iowa State University, Ames, IA 50011, USA \\ ${ }^{2}$ Evolution, Ecology \&' Genetics, Research School of Biology, The Australian National University, Canberra, ACT 0200, Australia
}

\begin{abstract}
Multiple mating or group spawning leads to post-copulatory sexual selection, which generally favours ejaculates that are more competitive under sperm competition. In four meta-analyses we quantify the evidence that sperm competition $(\mathrm{SC})$ favours greater sperm number using data from studies of strategic ejaculation. Differential investment into each ejaculate emerges at the individual level if males exhibit phenotypic plasticity in ejaculate properties in response to the likely risk and/or intensity of sperm competition after a given mating. Over the last twenty years, a series of theoretical models have been developed that predict how ejaculate size will be strategically adjusted in relation to: (a) the number of immediate rival males, with a distinction made between 0 versus 1 rival ('risk' of $\mathrm{SC}$ ) and 1 versus several rivals ('intensity' of SC); (b) female mating status (virgin or previously mated); and (c) female phenotypic quality (e.g. female size or condition). Some well-known studies have reported large adjustments in ejaculate size depending on the relevant social context and this has led to widespread acceptance of the claim that strategic sperm allocation occurs in response to each of these factors. It is necessary, however, to test each claim separately because it is easy to overlook studies with weak or negative findings. Compiling information on the variation in outcomes among species is potentially informative about the relevance of these assumptions in different taxa or mating systems.

We found strong evidence that, on average, males transfer larger ejaculates to higher quality females. The effect of female mating status was less straightforward and depended on how ejaculate size was measured (i.e. use of proxy or direct measure). There is strong evidence that ejaculate size increased when males were exposed to a single rival, which is often described as a response to the risk of SC. There is, however, no evidence for the general prediction that ejaculate size decreases as the number of rivals increases from one to several males (i.e. in response to a higher intensity of SC which lowers the rate of return per sperm released). Our results highlight how meta-analysis can reveal unintentional biases in narrative literature reviews. We note that several assumptions of theoretical models can alter an outcome's predicted direction in a given species (e.g. the effect of female mating status depends on whether there is firstor last-male sperm priority). Many studies do not provide this background information and fail to make strong a priori predictions about the expected response of ejaculate size to manipulation of the mating context. Researchers should be explicit about which model they are testing to ensure that future meta-analyses can better partition studies into different categories, or control for continuous moderator variables.
\end{abstract}

Key words: ejaculate size, mating rate, mate choice, multiple mating, polyandry, sexual selection, sperm competition, sperm size, sperm longevity, sperm viability.

\section{CONTENTS}

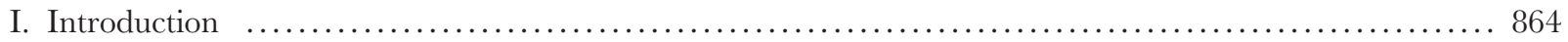

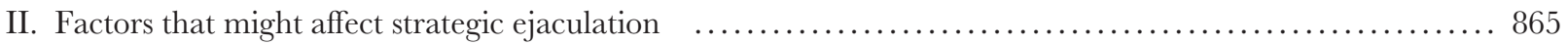

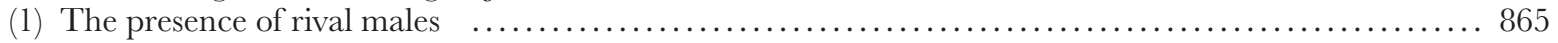

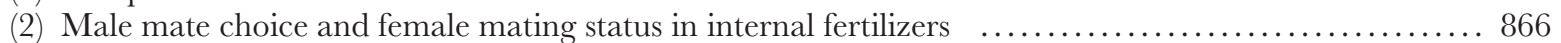

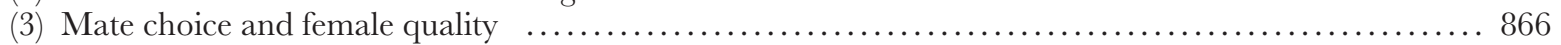

* Address for correspondence (E-mail: cdkelly@iastate.edu; Fax: +1 515294 1337; Tel: +1 515294 8511). 


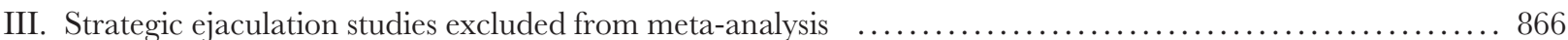

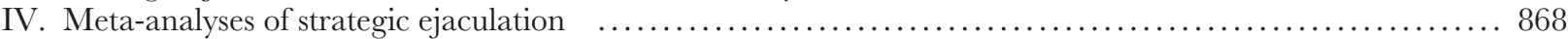

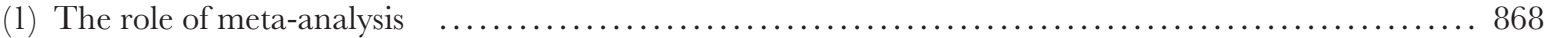

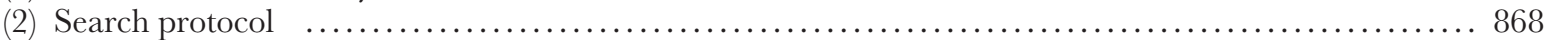

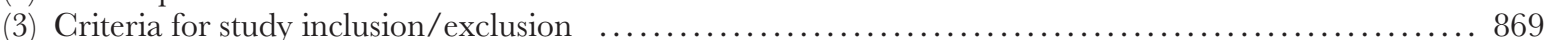

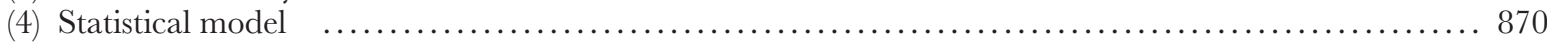

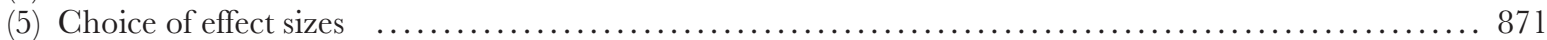

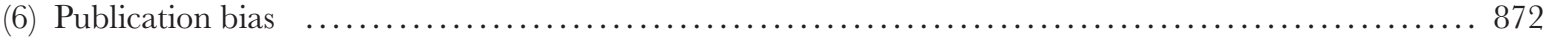

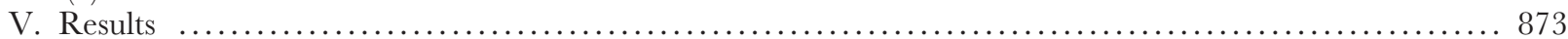

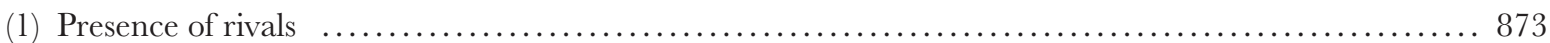

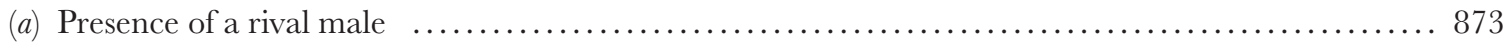

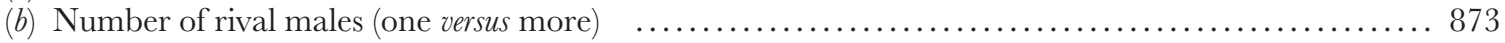

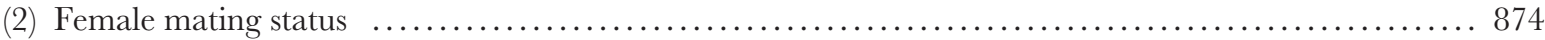

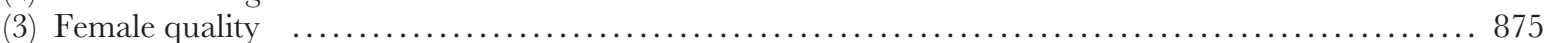

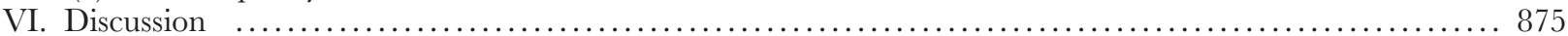

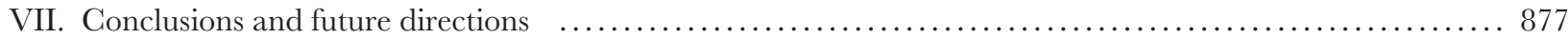

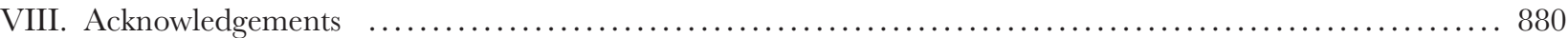

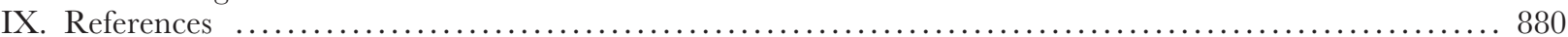

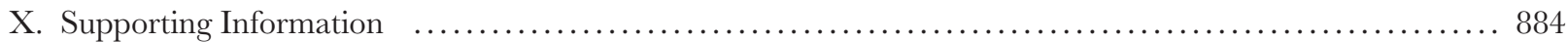

\section{INTRODUGTION}

Parker (1970) first outlined the concept of sperm competition and emphasised that sexual competition in internal fertilizers can persist after mate acquisition: if females mate multiply then sperm from two or more males can still compete for access to the same set of eggs. Sperm competition is a widespread phenomenon given that female multiple mating occurs in most internally fertilizing species (reviews: Jennions \& Petrie, 2000; Arnqvist et al., 2000; Griffith, Owens \& Thuman, 2002). Sperm competition also occurs in many external fertilizers, especially motile species where several males are present when females spawn (reviews: fish: Taborsky, 1998; frogs: Roberts \& Byrne, 2010).

As sperm production is costly (Dewsbury, 1982; Nakatsuru \& Kramer, 1982; Olsson, Madsen \& Shine, 1997), selection should favour facultative or strategic adjustment of ejaculate traits over a male's lifetime depending on the mating context (review: Wedell, Gage \& Parker, 2002). The phenomenon of strategic ejaculation in animals was first reported by Gage (1991) and Gage \& Baker (1991). The underlying premise of strategic ejaculation is that increasing sperm numbers or generating specific sperm traits is sufficiently costly that males adjust investment into ejaculates depending on the likely benefits. The rate of return from an ejaculate will depend on the number of eggs available to be fertilized, the likely quality of the resultant offspring (e.g. lower if the mating leads to inbred offspring), the risk that sperm competition occurs, and the likely intensity of any such sperm competition. It is now widely argued that males make exceedingly finescale adjustments in sperm numbers (review: Wedell et al., 2002) and, more recently, there has even been evidence that other sperm traits are adjusted in response to changes in the cost-benefit ratio. This might involve changes in the chemical composition of the ejaculate that lead to changes in sperm performance (review: Poiani, 2006; for a case study see Cornwallis \& O'Connor, 2009), or even in actual sperm morphology (Grean \& Marshall, 2008; Immler et al., 2010).

Although sperm quality (e.g. sperm viability, swimming speed, motility) and seminal fluid composition clearly influence male fertilization success in many species (Snook, 2005; Pitnick, Hosken \& Birkhead, 2009a; Pitnick, Wolfner \& Suarez, 2009b; Pizzari, 2009), it is important to bear in mind that total sperm number is currently the ejaculatory trait for which there is the strongest evidence of evolution in response to sexual selection imposed by sperm competition (Parker \& Pizzari, 2010). Relative numerical representation of sperm remains the single best predictor of male fertilization success under sperm competition. Indeed, almost all the current theoretical models developed to study 'sperm competition games' (sensu Parker, 1998) explore evolutionarily stable strategies for investment into numerical sperm production (for a recent extension of these models to consider both the sperm and non-sperm component of ejaculates see Cameron, Day \& Rowe, 2007).

In this review, we focus exclusively on evidence that ejaculate size (or proxy measures thereof), by which we mean sperm number $(s)$ evolves under postcopulatory sexual selection. We do so because: $(a)$ sperm number is the trait most likely to show phenotypic plasticity as rapid changes in production should be more easily achieved (i.e. at a lower cost than, say, adjusting total sperm length or the ratio of head to tail length); (b) the bulk of sperm competition theory is based on the premise that relative sperm number is the best predictor of each male's fertilization success (recent review: Parker \& Pizzari, 2010); (c) ejaculate size (or a proxy thereof) is the trait most often measured when testing for strategic ejaculation. Thus, a meta-analysis of strategic ejaculation through adjustment in sperm numbers should produce a sufficiently large data set to yield robust conclusions. Here, we extend the previous narrative review by Wedell et al. (2002) and conduct meta-analyses to assess claims that 
males adjust sperm numbers per ejaculate in response to variation in sperm competition arising from: $(a)$ variation in the potential number of rival ejaculates with which the focal male's ejaculate will have to compete; (b) female mating status (virgin or already mated); and $(c)$ differences in female phenotypic quality (e.g. infection status).

\section{FAGTORS THAT MIGHT AFFEGT STRATEGIC EJAGULATION}

Numerous models have been developed that focus on a wide range of scenarios under which males should adjust ejaculate size (see reviews by Parker, 1998, 2006; Pizzari \& Parker, 2009). Here, we focus on those models that are applicable across many taxa, and have therefore been tested more often. Specifically, we consider models that investigate the effect on ejaculate size of: $(a)$ the number of rival males present shortly before a male ejaculates; $(b)$ whether or not a female is a virgin; and $(c)$ female quality. Parker \& Pizzari (2010) have recently provided an invaluable survey of all the available sperm competition game models. The reader is specifically referred to models that make withinspecies predictions. These models motivated the studies that we analyse in our review. The model's assumptions and predictions are concisely summarized in Tables $4 \mathrm{~A}$ and $4 \mathrm{~B}$ of Parker \& Pizzarri (2010).

In general, the predictions of most sperm competition game models have been presented in terms of a unitless number that can be compared across species, namely the optimal proportion of reproductive effort expended on ejaculates $\left(E^{*}\right)$ when males have a fixed energy budget $(R)$ to invest into reproduction. $E=D s /(C+D s)$, where $D=$ cost associated with each sperm, $s=$ sperm number (i.e. ejaculate size) and $C=$ the cost of obtaining a mating. Hence, the maximum number of matings per male $(n)$ is $n=R /(C+D s)$ (i.e. total energy available for mating divided by total cost per mating). The number of matings per female that lead to sperm transfer, hence the actual level of sperm competition, will depend on the extent to which males or females control the effective mating rate (Fromhage, McNamara \& Houston, 2008). $E$ is often empirically measured using the surrogate of relative testes size (Parker \& Ball, 2005). If $C$ and $D$ are fixed, then $E$ and $s$ are always positively related and predictions about directional change in response to sperm competition can be applied interchangeably to both $E$ and $s$. However, recent 'consistent' models which are mainly aimed at generating predictions across species or populations have allowed the level of sperm competition (i.e. changes in $n$ when adult sex ratio stays the same) to evolve as other model parameters, including $s$, change (see Parker \& Ball, 2005; Williams, Day \& Cameron, 2005; Engqvist \& Reinhold, 2006; Cameron et al., 2007; Ball \& Parker, 2007; Fromhage et al., 2008; Tazzyman et al., 2009). This has led to predictions about cross-species patterns that differ from those of earlier models. Predictions about $E$ and $s$ are therefore no longer interchangeable. We mention this only because there is still confusion about across and within-species predictions and if they differ depending on whether ejaculate size or relative testes size are being measured. Here, we are only interested in within-population predictions about facultative changes by males to produce the optimal ejaculate size $\left(s^{*}\right)$ in response to the likely risk/intensity of sperm competition associated with a given mating. In such a context, it is generally assumed that $D$ and $C$ do not vary systematically among matings so the same predictions can also be made with reference to $s$ or $E$ (with the caveat that $E$ can not be measured empirically using relative testes size because it is assumed that phenotypic plasticity in $s$ does not involve a simultaneous change in testes size associated with each ejaculate). Parker \& Pizzari (2010) provided a useful overview of the differences and similarities between recent 'consistency' and earlier sperm competition game models, and we refer the reader to their review for further details.

\section{(1) The presence of rival males}

The plethora of sperm competition game models are broadly divided into those that consider variation in sperm competition risk (whether or not it occurs) or intensity (number of ejaculates competing for a set of eggs) (Parker, 1998; Engqvist \& Reinhold, 2005). The 'risk' models investigate the effect of variation in $q$ (the probability that two ejaculates compete). Risk models are usually envisaged in terms of internal fertilizers and the likelihood that a female will mate twice, while 'intensity' models are framed in terms of external fertilization and variation in the number of males $(\mathcal{N})$ ejaculating when a female spawns (Parker et al., 1996, 1997). They can, however, be applied to both fertilization modes.

In species where most breeding events involve sperm competition (i.e. most females mate multiply or group spawn so that $q \approx 1$ ), within-species 'intensity' models predict that the proportion of effort expended on ejaculates $\left(E^{*}\right.$ or $\left.s^{*}\right)$ decreases as the number of males competing in a given reproductive event $(\mathcal{N})$ increases beyond two (Parker et al., 1996; Parker, 1998). On the contrary, as sperm competition risk increases within a species, $E^{*}$ or $s^{*}$ is predicted to increase (Parker et al., 1997; Parker, 1998). For example, if males have perfect information about the number of males that will mate/spawn with a female, $N_{\mathrm{i}}$, and the distribution of males per reproductive event follows a Poisson distribution with mean $\mathcal{N}_{\mathrm{m}}$ then $E^{*}{ }_{\mathrm{i}}=\mathcal{N}_{\mathrm{m}}\left(\mathcal{N}_{\mathrm{i}}-1\right) / \mathcal{N}_{\mathrm{i}}^{2}$, where $\mathrm{E}^{*}{ }_{\mathrm{i}}$ is the proportion of effort spent on ejaculates. There is an increase in $E^{*}$ as $\mathcal{N}_{\mathrm{i}}$ increases from a solitary male without sperm competition so that $E^{*}{ }_{1}$ is the minimum required to fertilize eggs, to a maximum value of $E^{*}$ when there are two males (i.e. the risk of sperm competition qgoes from 0 to 1 ), but thereafter as $\mathcal{N}_{\mathrm{i}}$ increases, $E^{*}$ declines. This is a consequence of each released sperm's value diminishing because the number of eggs available remains constant while the total number of sperm (due to the participation of more competitors) increases. The marginal returns from the release of additional sperm are reduced so the optimal ejaculate size decreases (Parker et al., 1996). 
Thus, within-species sperm competition risk and intensity models yield the simple prediction that the presence of one rival will increase the risk of sperm competition so that ejaculate size will increase when comparing males that mate alone versus in the presence of a single rival. By contrast, once sperm competition is likely, the presence of additional rivals will increase the intensity of sperm competition. Hence, there should be a negative relationship between ejaculate size and male rival number when there are one or more rivals present. Our general predictions agree with the summary provided by Parker \& Pizzari (2010, Point 8, p.931) that: "sperm allocation is likely to be highest with one competitor, reducing as the number of competitors increases."

\section{(2) Male mate choice and female mating status in internal fertilizers}

Several studies show that, in at least some species, males have access to cues that indicate whether a female has mated and that this affects male mate choice (review: Bonduriansky, 2001). For example, Zahradnik, LeMay \& Boulding (2008) showed that male snails preferentially chose to mate with virgin females. Similarly, in a spider where females have two genital openings that lead to separate sperm storage chambers, males preferentially inseminated sperm into the unused opening (Jones \& Elgar, 2008). In some cases, the proximate cues used to detect female mating status are known (e.g. odour in guppies: Guevara-Fiore, Skinner \& Watt, 2009; pheromones in crickets: Thomas \& Simmons, 2009). It is therefore plausible that males adjust ejaculate size as a cryptic form of mate choice in response to female mating status if status predicts the likely intensity and/or risk of sperm competition.

The obvious starting point of any model is that a virgin female might not mate again, while a mated female already contains sperm from a rival. Using the classic 'risk' model we predict that ejaculate size should be smaller for virgin females (e.g. Parker et al., 1997; Ball \& Parker, 1998) as the risk that the male will face sperm competition is smaller. The problem, however, is that when females mate multiply the intensity of sperm competition increases and, by simple rules of conditional probability the probability that a virgin female will mate a given number of times is smaller than that for an already mated female (Engqvist \& Reinhold, 2006). This difference in the intensity of sperm competition makes the counter-prediction that males should allocate more sperm to virgin females. The optimal ejaculate size to produce is not obvious, however, because there is also an asymmetry in the information available to males mating with virgins and non-virgins (males mating with virgins have less information about the final intensity of sperm competition). Engqvist \& Reinhold (2006) ran a simulation model to determine the optimal ejaculate size if males can distinguish between virgin and mated females. They showed that males should produce larger ejaculates when mating with virgins if female remating rates are high, and smaller ejaculates when remating rates are low. They also show that first-male sperm priority selects for larger ejaculate size and last-male priority for smaller ejaculate size when mating with virgin rather than already mated females. Using a game theory approach and a modified 'risk model', Ball \& Parker (2007) also found that first-male sperm priority, a high average risk of sperm competition and sperm limitation can select for larger ejaculate size with virgins. In practice, many researchers still invoke the original model of Parker et al. (1997) that predicts that males should transfer larger ejaculates to mated females. As a working hypothesis we treat this as the 'standard' prediction in our meta-analysis. We acknowledge that it would be preferable to exclude studies where we could confidently conclude that: "the raffle is loaded in favour of the first male to mate and there is either $(i)$ a high mean level of sperm competition or (ii) sperm limitation" (Parker \& Pizzari, 2010, Point 8 on p.931). At present, however, it is difficult to obtain this level of background detail for most studies.

\section{(3) Mate choice and female quality}

Reinhold, Kurtz \& Enqvist (2002) showed that female quality has a strong effect on sperm allocation. Their simulations predicted that males should invest more sperm in copulations with higher quality females, assuming males can reliably assess mate quality. If, on the other hand, males cannot assess mate quality they should invest more sperm into the first copulation. Increasing the variance in female quality led to males conserving sperm for later copulations whereas low variance caused males to make higher allocations to initial matings. From this model we predict a positive relationship between female quality and ejaculate size. It should, however, be noted that models of male mate choice suggest that when all males prefer the same females, the value of these females deceases due to greater competition, so that there is selection for male quality-specific mate choice (e.g. Härdling, Gosden \& Aguilee, 2008). By the same token, it seems possible that variation in quality among males could affect whether individual males transfer more or less sperm to higher quality females. We are unaware of any formal model of this scenario. It is likely that none exists given that Tazzyman et al. (2009) claim they are the first to model continuous variation in male quality (resource acquisition and cost of mating). Again, however, we note that our general prediction agrees with the summary provided by Parker \& Pizzari (2010, p.931) that: "males are most likely to allocate more sperm to more fecund females, though this need not always be the case, and will be moderated by seasonal effects".

\section{STRATEGIC EJAGULATION STUDIES EXGLUDED FROM META-ANALYSIS}

Our four meta-analyses cover the effect of rival presence/absence, an increase in the number of rivals, female quality and female mating status on strategic ejaculate with respect to sperm quantity (i.e. ejaculate size). The criteria for inclusion of studies in our meta-analyses are listed in 
Section IV.3. Clearly, however, there are additional studies that take advantage of other circumstances that affect the value of a mating and can therefore be used to test for strategic changes in ejaculate size. We describe these studies to encourage researchers to test for these effects in more species so that they will be amenable to future meta-analysis as data accumulate.

(A) Many studies, rather than looking at immediate plastic changes in ejaculate size, have examined longerterm developmental (ontogenetic) shifts in investment into sperm production due to social rearing conditions (sex ratio and/or population density) that could be linked to the level of sperm competition. There are good theoretical reasons to consider ontogenetic and immediate-response studies separately (review: Engqvist \& Reinhold, 2005). There is a positive relationship between larval rearing density and ejaculate size in a moth (Plodia interpunctella) (Gage, 1995) and dungfly (S. stercoraria) (Stockley \& Seal, 2001). In a study of six strains of a seed beetle (Callosobruchus chinensis), however, males reared at a high density had a significantly smallersized ejaculate in two strains, significantly large-sized in one strain and there was no difference in the other three strains (Yamane \& Miyatake, 2008). There was also no relationship between rearing density and testis size in the bruchid beetle (Callosobruchus maculatus) (Gay et al., 2009) nor between larval culture density and the number of sperm transferred in D. melanogaster (McGraw et al., 2007).

Two studies have reported a positive relationship between larval rearing density and apyrene, but not eupyrene, sperm numbers: armyworm (Pseudaletia separata) (He \& Miyata, 1997) and the moth Cadra cautella (McNamara, Elgar \& Jones, 2010). Similarly, longer term presence of potential rivals leads to the evolution of greater investment in testes by the socially dominant male in a group-living cichlid fulidochromis ornatus (Awata et al., 2006, 2008). There are also effects of female presence/absence. For example, in the cockroach Nauphoeta cinerea, focal males were housed with either males or females during the final period of adult maturation. Those housed with females had a larger ejaculate size for the first, but not second, mating (Harris \& Moore, 2005). More generally, 'sperm priming' (rapid increase in sperm availability) in response to female presence has been reported in many fish (references in Evans, 2009). Similarly, in a fruitfly (Drosophila bifurca) variation in exposure to females (and males simultaneously) affected the rate of sperm production (Bjork, Dallai \& Pitnick, 2007).

In several simultaneous hermaphrodites changes in testes and/or ejaculate size (often described as shifts in sex allocation) have been reported in response to changes in density and sex ratios (e.g. Schärer \& Ladurner, 2003; Loose \& Koene, 2008; Janicke \& Schärer, 2009). We do not consider these cases further because of the challenge of distinguishing between selection for greater investment in sperm production or greater investment in eggs (with a decline in sperm production as a by-product due to tradeoffs), as well as strong trade-offs with other sex-specific characters. Schärer (2009) provides an excellent review of this topic and the slightly different theory used to explain investment in male and female traits while accounting for the Fisher condition (see Kokko \& Jennions, 2008).

(B) Evidence for strategic ejaculation with respect to sperm quantity comes from studies investigating the familiarity/novelty of a female ('the Coolidge effect') and/or the number of times a male has already mated with a female on male mating propensity. In general, there is good evidence for a greater reluctance of males to mate repeatedly with a familiar female (Dewsbury, 1981; Koene \& Ter Maat, 2007; Steiger et al., 2008: but see Gershman \& Sakaluk, 2009; Haederer et al., 2009). It is possible, however, that females also contribute to this pattern if they prefer novel males (e.g. Bateman, 1998; Archer \& Elgar, 1999; Xu \& Wang, 2009). There is less evidence for the allied idea that males produce larger ejaculates when exposed to novel females (Pizzari, 2002). This has been shown in domestic fowl (e.g. Pizzari et al., 2003) but not in a cricket (Gryllus sigillatus) (Gershman \& Sakaluk, 2009), or snails (assuming copulation duration predicts ejaculate size) (Haederer et al., 2009).

General patterns of changes in ejaculate size over successive matings with novel females can also be tentatively interpreted as a strategic response to the general likelihood of her obtaining additional matings and/or temporal changes in the level of sperm competition intensity (e.g. Pitnick \& Markow, 1994). This can result in differential changes in ejaculate size with mating order depending on a male's social status (e.g. Cornwallis \& Birkhead, 2006).

(C) There is evidence that males can strategically adjust ejaculate size based on short-term responses to their current social status (e.g. Cornwallis \& Birkhead, 2006, 2007; Vaughn, delBarco-Trillo \& Ferkin, 2008).

(D) Given the lower fitness of inbred offspring it is generally argued that males will transfer fewer sperm to related females. This type of phenotypic plasticity is, however, unlikely to evolve unless the potential for mating with relatives is common. In support of this claim, in a moth (Plodia interpunctella), males ejaculate fewer eupyrene (and apyrene) sperm when mating with their sisters than they do when mating with an unrelated female (Lewis \& Wedell, 2009). No such difference was seen in a cricket (Gryllodes supplicans) (Stockley, 1999), and in domestic fowl, males inseminate more sperm when mating with a related female (Pizzari, Lovlie \& Cornwallis, 2004). This final study raises the wider issue that sexual conflict can select for male traits that overcome female resistance to being inseminated by lower quality males (in this case, less-compatible related males) (Parker, 2006). Hence, an increase in ejaculate size might not be solely due to a change in the value of a mating for a male, but also in the rate of return per sperm released. In addition, kin selection can sometimes favour females that allow related males to sire their offspring if the mating opportunities for these males are otherwise low (Kokko \& Ots, 2006). It is therefore not a priori true that males should transfer a smaller ejaculate to related females.

(E) It has been suggested that, as with genome-wide relatedness, male-female genetic compatibility at key loci 
could also lead to strategic ejaculation. In general, greater diversity at the major histocompatability complex (MHC) leads to higher fitness by elevating immune function (Milinski, 2006; Kekäläinen et al., 2009). In domestic fowl, males allowed to mate with two females allocated relatively more sperm to the more genetically dissimilar of the two with respect to MHC alleles (Gillingham et al., 2009).

(F) The number of sperm transferred in species complexes where asexual females require sperm to trigger embryogenesis is an unusual test case for strategic ejaculation. Males mate with both conspecifics and asexual heterospecifics. One such complex in Poecillid fish involves an asexual (Poecilia formosa) and two sexual species (P. latipinna and $P$. mexicana). Male $P$. latipinna produce more sperm when in the presence of a conspecific than a heterospecific female, indicating that there is some level of mate recognition (Aspbury \& Gabor, 2004). P. mexicana males appear to transfer more sperm to conspecific than asexual females, although this seems primarily to reflect a greater rate of copulation with conspecifics (Schlupp \& Plath, 2005). Intriguingly, however, another study showed that male P. latipinna had more sperm reserves available after mating with a conspecific than with an asexual female, although it is still unclear whether this means that males transferred more sperm to asexuals or that initial interactions with sexual females promoted greater sperm production (Robinson, Aspbury \& Gabor, 2008). We mention these studies because they are frequently cited as though they offer evidence for strategic ejaculation. In our view this conclusion is not warranted and they should not be cited as such.

\section{META-ANALYSES OF STRATEGIC EJAGULATION}

\section{(1) The role of meta-analysis}

We use meta-analysis to review hypotheses of strategic ejaculation. This method is superior to narrative review because the latter has a number of inherent problems, specifically: (1) the potential for biased sampling of the available studies. This happens because studies with significant results are more often cited and/or published in familiar journals ('publication bias'), and are therefore more likely to be located when conducting a non-systematic review (see Jennions et al., 2011c); (2) narrative reviews use 'vote counting' whereby studies are classified as either showing or not showing an expected relationship (i.e. $P<0.05$ or $P>0.05$ ). This crude dichotomy ignores the role of differences in sample size (affecting the relative confidence we have in a given relationship's estimated strength) and statistical power [i.e. in much of ecology and evolution, effect sizes are small so that non-significant results are common (Møller \& Jennions (2002)]. The net result is that very large numbers of studies are required to detect moderate or weak relationships when using vote counting (Koricheva \& Gurevitch, 2011).
There is widespread acceptance that strategic sperm allocation occurs in response to female mating status, female quality and the presence of rival males that alter the risk and/or intensity of sperm competition (review: Wedell et al., 2002). This is partly the result of a few influential studies that clearly show that sperm competition affects phenotypic plasticity in ejaculate size (e.g. Gage 1991; Pizzari et al., 2003, delBarco-Trillo \& Ferkin, 2004). It is important, however, to test the generality of such findings to avoid the tendency preferentially to cite studies with positive findings and ignore those that produce anomalous or inconclusive results. It is already clear that tests of strategic ejaculation have produced results that cover the full range of possible outcomes. For example, studies show that males allocate more sperm to virgins, less sperm to virgins and that female virginity has no effect on ejaculate size (Engqvist \& Reinhold, 2006, p.1455). In such cases, meta-analysis can help to determine whether variation is due to sampling error, low statistical power or if study heterogeneity can be accounted for by locating moderators of the proposed effect. There have been recent explicit calls for a meta-analysis of questions relating to ejaculate economics (Parker \& Pizzari, 2010, p.924).

In addition, theoretical models that make slightly different assumptions can generate contrasting predictions about the direction of shifts in ejaculate size (e.g. models investigating the effect of female virginity; Engqvist \& Reinhold, 2006). Given that researchers often have a limited ability to test model assumptions directly (and the reality that many theoretical models are not designed to be tested directly because they 'oversimplify' the world) it is often informative simply to quantify the direction of changes in ejaculate size in response to a factor of interest. Empiricism has its place. The resultant effect sizes can be used to assess the likelihood that some assumptions are more likely than others to apply in nature. Investigation of the source of among-studies differences in effect size can also provide insights into factors that might have been ignored in earlier theoretical models, or highlight methodological issues that bias outcomes (Jennions, Lortie \& Koricheva, 2011a). To address these issues we conducted a systematic review of the literature and performed a meta-analysis to determine how female quality, mating status and the presence/number of rival males affects short-term changes in ejaculate size.

\section{(2) Search protocol}

Systematic reviews (including meta-analyses) by biologists often provide insufficient details of the protocol used to locate studies, the inclusion criteria and decisions made when extracting data from publications (reviews: Pullin \& Stewart, 2006; Côté et al., 2011, Curtis et al., 2011). We therefore provide a more detailed account of our protocol than is usually presented in ecology and evolution metaanalyses. The main goal of our search protocol was to locate as many studies as possible while minimizing sampling biases. Adding papers that are spotted in the general course of reading the literature can move one closer to the goal of locating all available studies. However, this can also bias 
a meta-analysis because one more often encounters the content of higher- than lower-impact-factor journals (i.e. citation rates of studies affect their 'visibility'), and there is evidence that effect sizes are larger in high-impact journals (Murtaugh, 2002; in medicine see Baker \& Jackson, 2006). Similarly, there is evidence that studies in prestigious journals are more likely to support than refute prevailing hypotheses (Leimu \& Koricheva, 2005).

Our literature search strategy involved three approaches. First, we searched the Web of Science (SCI-Expanded) from 1945 to June 2009 using the following search terms entered into the 'topic' window (i.e. in title, abstract or key words). The terms were "sperm expenditure", "ejaculate expenditure", "strategic mating", "sperm allocation", (strategic AND sperm), (strategic AND ejaculat*), ("rival male" AND sperm), ("male-male" AND ejaculat*), ("female age" AND sperm), ("female body size" AND sperm), ("female size" AND sperm), ("female mat* status" AND sperm), ("female quality" AND sperm) and ("copulation duration" AND "sperm competition"). These terms were selected to maximise the likelihood that we located suitable studies within the constraints of ensuring that the resultant dataset was of a manageable size to actually inspect relevant papers. This search yielded 924 publications.

Second, our initial scoping search of the literature (see Stewart et al., 2011) identified five 'classic' empirical papers that are widely regarded as 'landmark' papers. These papers are: Gage (1991), Gage \& Baker (1991), Gage, Stockley \& Parker (1995), Shapiro, Marconato \& Yoshikawa (1994) and Gage \& Barnard (1996). All five papers are highly cited (95-133 times each by the end of 2009) and likely to be cited by most authors investigating strategic allocation of sperm. The same is true of a recent, influential review of sperm allocation by Wedell et al. (2002) (cited 294 times by the end of 2009). We used Web of Science in June 2009 to identify any paper that had cited at least one of these six papers. In total, we located 624 papers using this approach. There was a strong overlap between the papers located by the two approaches as the combined database contained 1101 unique peer-reviewed journal publications (see Section X. Supporting Information for reference database). We then inspected the titles, place of publication and, where possible, the online abstract to perform an initial cull (review: Côté et al., 2011). We excluded papers that were clearly irrelevant or highly unlikely to contain suitable studies (see Section IV.3). Papers that potentially contained relevant data, or which had to be read more closely to assess their suitability, were then acquired and examined to see if they met our inclusion criteria.

We draw the reader's attention to three aspects of our search strategy. First, we did not solicit unpublished datasets from colleagues. This was based on our previous experience that the number of additional effect sizes obtained through this strategy is extremely low, and there is often controversy about the quality of such studies. We decided that our effort was better expended using broad search terms to create a larger initial pool of potentially usable papers. More importantly, there is an unavoidable tendency primarily to contact established researchers (i.e. those who publish regularly on the focal topic). This might introduce a sampling bias if they have unpublished results that are, for example, more often non-significant than those of a random sample of researchers working on the same topic. For example, productive researchers who complete many studies might be more inclined to publish their 'best' results first while less productive researchers, or those who abandon research careers, might fail to publish irrespective of the statistical significance of their findings. It is worth noting, however, that there is little evidence that effect sizes differ between published and unpublished datasets in ecology and evolution (review: Jennions et al., 2011c).

Second, we did not search the 'grey literature' (e.g. government reports, non-English-language journals not covered by Web of Science, conference abstracts, $\mathrm{PhD}$ theses and so on). Our questions concern a strongly theory-driven area of evolutionary biology and it is unlikely that suitable data would be found in government reports and allied sources. It is, however, possible that some unlocated $\mathrm{PhD}$ theses and conference abstracts contain suitable studies. Again, however, there is always concern that such studies remain unpublished due to issues about quality or data reliability. Finally, there is some evidence that non-Englishlanguage publications tend to report smaller effect sizes, arguably because authors invest more effort writing in their second language when they have significant results (Jennions et al., 2011c).

Third, we have not added papers drawn to our attention since June 2009. This was a deliberate decision to reduce any sampling bias while updating our dataset. We are aware that seemingly suitable studies have since appeared (e.g. Evans, 2009; Teng \& Zhang, 2009; Larsdotter-Mellstrom \& Wiklund, 2009; Cornwallis \& O'Connor, 2009). We do not claim to have located all relevant studies, but by clearly stating our protocol the reader can decide whether we are likely to generate biased estimates of the true effect sizes. It is worth recalling that all meta-analyses are provisional, and should be regularly updated (for criteria see Moher et al., 2008). There is, for example, evidence for temporal changes in estimates of effect sizes in ecology and evolution (e.g. Jennions \& Møller, 2002; review; Koricheva, Gurevitch \& Mengersen, 2011). We therefore present analyses examining temporal trends in Section V. That said, we encourage readers aware of usable studies that we have overlooked to send us details so that we can revise our search protocol to ensure additional suitable papers are located using a more inclusive search strategy (e.g. different search terms) when the current meta-analysis is updated.

\section{(3) Criteria for study inclusion/exclusion}

As part of a systematic review it is necessary to establish study inclusion criteria (Côté et al., 2011). In our case, these were: (1) does the study fit the scope of our questions; (2) does the methodology/study design fit with how our questions are defined; (3) does the study contain extractable data? Our 
main study questions were whether across all animal taxa the mean within-species relationship differs from the null value for that between ejaculate size and the following variables.

(a) Number of rival males present. The question was subdivided to examine ( $i$ ) ejaculate size in the presence and absence of a single rival (0 versus 1 rival); and (ii) ejaculate size in the presence of a single rival compared to two or more rivals ( 1 versus $2+$ rivals). The study therefore must compare ejaculate size between males in groups in which the focal male was allowed to mate shortly after, or while still in the presence of $0,1,2$ or more than 2 rival males.

(b) Female mating status: virgin versus previously mated female. The study therefore must compare ejaculate size between males in groups in which the focal male was allowed to mate with either a virgin or previously mated female.

(c) Female quality. The quality measures we considered were body size, age, infection status, body weight, bilateral symmetry, body condition and sexual ornament size. The study had to report the correlation between the female trait and ejaculate size.

We were only interested in short-term adjustment of ejaculate size by males, rather than long-term ontogenetic development (see Section II). We therefore only included studies where focal males were assigned to sperm competition treatment groups after they had reached sexual maturity. In most of the included studies, males were experimentally assigned mates or rivals so changes in ejaculate size are causally related to the number of rivals or female phenotype. The study also had to report an index of ejaculate size. Ideally, the study directly counted sperm number in the ejaculate (by definition 'ejaculate size'). The other six proxy indices we accepted were: number of sperm remaining in the male after ejaculation, sperm volume, spermatophore mass, copulation duration, ejaculation rate and the number of ejaculations during a mating bout. Most of the original papers provide the researchers' own evidence as to why these proxy measures of ejaculate size will correlate with total sperm number. We excluded studies (or sets of data within studies) that only reported the extent of dilation of the female spermathecae after mating (Wang \& Millar, 1997), and those where it was impossible to partition the total sperm count into the relative contribution by competing males (e.g. nesting versus sneaker and satellite males; Alonzo \& Warner, 2000). In our analysis we distinguish between effect sizes based on the direct measure of counting the sperm in an ejaculate, and the other six proxy measures. We did not pursue a finer-scale categorization of studies using different types of proxy measures as the sample sizes were then too small for a robust statistical analysis. We excluded studies on humans (e.g. Kilgallon \& Simmons, 2005), partly because some of these papers are very difficult to interpret (e.g. Baker \& Bellis, 1989). We excluded effect sizes for Lepidoptera that were based on apyrene sperm counts, but included those based on eupyrene sperm count (Wedell \& Cook 1999a,b).
Even when a study fulfilled the 'design' criteria, in several cases we were still unable to include it because the results were presented in an ambiguous manner that prevented us from extracting an effect size. This is a common problem in most meta-analyses and we tried to err on the side of caution (Curtis et al., 2011), which is why some studies that the reader might think appropriate were excluded. For example, we excluded studies (or sets of data within studies) in which the direction of the effect was unclear to us (e.g. Pound \& Gage, 2004), when only medians (e.g. Alonso-Pimentel \& Papaj, 1996; Schofl \& Taborsky, 2002) or interaction effects were provided (e.g. Simmons \& Kvarnemo, 1997), or when the analysis involved obvious pseudoreplication that inflated sample sizes (e.g. Shapiro et al., 1994; Marconato, Tessari \& Marin, 1995; Marconato \& Shapiro, 1996).

It is difficult to calculate the appropriate sample size when using the degrees of freedom from $F$-statistics from mixed models. Depending on the data, the value lies between $\mathcal{N}-p$ (if $R=0$ ) and $k-p$ (if $R=1$ ), where $\mathcal{N}$ is the total sample size, $p$ is the number of model parameters, $k$ is the number of groups and $R$ is the repeatability. In addition, some statisticians recommend that the denominator degrees of freedom reflect the appropriate strata of analysis (e.g. Bates \& Pinheiro, 2002, p.91). There is ongoing uncertainty about the most appropriate method to test the significance of fixed effects (e.g. Markov Chain Monte Carlo, log-likelihood ratios, $F$ statistics from parameter estimates). In the one case where this issue arose (Pizzari et al., 2003) we set the sample size as 128 to reflect the number of ejaculates examined.

We retrieved data from the text or tables, or indirectly by extracting data from figures using GraphClick (Arizona Software). In 11 cases, we contacted first authors of papers in which the requisite statistics were unavailable: seven authors provided data, two did not respond, one responded after the analyses were complete and another declined to provide data.

\section{(4) Statistical model}

In general, we followed standard meta-analytical procedures (for two user-friendly introductions see Borenstein et al., 2009; Koricheva et al., 2011). The first issue to cover is how we dealt with statistically non-independent data. We considered effect sizes addressing different questions as independent (i.e. the datasets used to address each of the four questions were treated as independent). Within each dataset, by definition, we treated as non-independent, multiple effect sizes for a given species in the same publication and, at a higher level, effect sizes from different studies of the same species. We eliminated this non-independence by first calculating a single mean effect size and variance for each species-study combination (i.e. one per study unless the study was multispecies) using a standard random model meta-analysis. We then used these values to calculate the mean and variance for each species, again using a standard random model meta-analysis (for worked examples and alternative methods to handle correlated data, see Borenstein et al., 2009). Each species therefore provided a single effect size for the final meta-analysis for each of our four main questions. 
We did not correct for higher level phylogenetic relatedness (Adams, 2008; Lajeunesse, 2009; Hadfield \& Nakagawa, 2010) because of the very wide taxonomic spread of our dataset (i.e. molluscs to mammals); the difficulty of compiling a phylogenetic supertree for Animalia notwithstanding (Gatesy, Baker \& Hayashi, 2004; Wiens, 2003), such an effort would also require estimating branch lengths (Díaz-Uriarte \& Garland, 1998). This is a non-trivial task, particularly if relatively few taxa are sampled (e.g. Linder, Hardy \& Rutschmann, 2005). Moreover, a supertree that includes only a few orders spread across Animalia would involve extreme taxon sampling and tree pruning, resulting in no sizable component of shared history among taxa for which to control (see Björklund, 1997). It is worth noting that we tested for effect size differences among higher level taxa (e.g. between mammals, fish and insects). In two tests the effect sizes did not differ significantly, and in the other two cases the differences have to be viewed with extreme caution due to low sample sizes for one or more taxa (see Section V). Regardless, we also present mean effects separately for each group of taxa so that the reader can infer how each group of taxa contributes to the pooled mean effect. We only treated studies as 'independent' when study identity was the focus of the analysis (i.e. in a cumulative meta-analysis or when considering the relationship between publication date and effect size). Here, the mean effect size and variance was calculated for each study and used in the analysis.

All statistical analyses were performed in the $R$ environment ( $R$ Version 2.8.0; R Development Core Team, 2008). Mean effect sizes were calculated using randomeffects models that attribute variation in effect size among studies to both sampling error and true random variation among studies that is estimated from the data (Hedges \& Olkin, 1985). The null hypothesis for each analysis was that the mean effect size equaled zero. For each study question, $\mathcal{N}$ species-level effect sizes were entered into a generalized linear model (GLM) with effect sizes weighted by the inverse of their variance. To test whether the mean effect size estimate differed from the null value, we used a $t$-test with $\mathcal{N}-1$ degrees of freedom to determine whether the model intercept was significantly different from zero. We also report the total heterogeneity $\left(Q_{T}\right)$ in species-level effect sizes, assuming that $Q$ follows a $\chi^{2}$ distribution with d.f. $=\mathcal{N}-1$. Significant heterogeneity indicates that the variance is greater than expected solely due to sampling error, suggesting that it is worthwhile searching for moderators (categorical or continuous) that might explain variation in effect size values among species (e.g. method of measurement, taxonomic grouping). Mean weighted effect sizes obtained using $Z_{r}$ (Fisher transformation of $r$ ) were back-converted to $r$. We present $95 \%$ confidence intervals using standard formulae.

For each of the four meta-analyses, we calculated separately the mean effect size when the measure of ejaculate size was based on a direct sperm count or an indirect, proxy measure. We tested whether the mean effect size differed significantly between the two measures using a test for significantly greater variance between than within groups (i.e. $\left.Q_{b}\right)$. Strictly speaking, as with any analysis of variance (ANOVA), it is only warranted to investigate the source of variation in effect sizes among groups if $Q_{T}$ is significant. However, several recent meta-analyses in evolution and ecology have identified significant moderators of effect size even when $Q_{T}$ was not significant (Jennions, Lortie \& Koricheva, 2011b). There is also concern that low power can lead to a non-significant $Q$ estimate despite substantial between-study dispersion in effect sizes (see Borenstein et al., 2009, p.113). We therefore also tested (where sample size permitted) for difference in effect sizes due to taxon, fertilization mode (internal versus external) and female trait type (for quality). It should be noted that only one factor at a time is considered. If there is covariation between factors then it can be difficult to determine which is the more important predictor. Unfortunately sample sizes are too small to perform more sophisticated analyses that control for the effect of other factors.

\section{(5) Choice of effect sizes}

In most studies investigating the effect of rival males on ejaculate size, a comparison was made between focal males experimentally assigned to different categories (e.g. no rival, one rival, two rivals, three rivals). We therefore used the effect size Hedge's $d$ which is designed to compare two groups. Hedge's $d$ is Cohen's $d$ corrected for a sample size bias using 7 . Please note that in Metawin 2.0, Rosenberg, Adams \& Gurevitch (2000) refer to this effect size as Hedge's $d$ but recent textbooks (e.g. Cooper, Hedges \& Valentine, 2009) refer to it as Hedge's $g$. Here we use Rosenberg et al.'s (2000) definition. If a study contained the requisite male categories we calculated separate effect sizes for the effect of no rival versus one rival male and for one rival versus more than one rival male. Many studies only had one experimental group with more than one rival. When there was a choice, we used the group with the largest number of rivals. The formula we used for Hedge's $d$ was: $d=$ Cohen $d^{*} \mathcal{F}$, where $\mathcal{F}=1-3 /\left[4\left(n_{\mathrm{a}}+n_{\mathrm{b}}\right)-9\right]$. Here, Cohen $d$ is the standardised difference in means between two groups: Cohen $d=\left(x_{\mathrm{a}}-x_{\mathrm{b}}\right) / \mathrm{SD}_{\text {pooled }}$.

where $x_{\mathrm{a}}$ and $x_{\mathrm{b}}$ are the mean ejaculate size of males exposed to one rival and no rivals or two or more rivals and one rival, respectively, and $n_{\mathrm{a}}$ and $n_{\mathrm{b}}$ are the associated sample sizes. The pooled standard deviation is calculated following equation 12.12 and the variance in $d$ following equation 12.13 (multiplied by $\tilde{f}^{2}$ ) in Cooper et al. (2009) (the same equations are in Rosenberg et al., 2000). These equations require that we know the sample size and standard deviation for both groups being compared. In a few studies, data were presented as the correlation between ejaculate size and the number of rivals (excluding zero). We therefore had to convert $r$ to $d$ (for formulae see Cooper et al., 2009, p.233-234). We predicted that the effect size for the 0 versus 1 rival male treatment would be significantly positive (larger ejaculate size with one rival present), whereas the 
effect size for the 1 versus $2+$ rival males treatment would be significantly negative (smaller ejaculate size with more rivals) (see Section II).

In cases where a species provided an effect size for both the 0 versus 1 and 1 versus $2+$ treatments we can calculate the effect size Cohen's $q$ which is simply the difference between the effect sizes, with a variance that is the sum of the two original variances (Borenstein et al., 2009). Testing whether Cohen's $q$ differs from zero when $q=d_{0 v s 1}-d_{1 v s 2+}$ controls for variation in effect sizes among species to test whether the effect size for the effect of rival presence/absence (sperm competition risk) differs from that for rival number (sperm competition intensity). We can also test whether the two effect sizes are equal in magnitude but opposite in direction by setting $q=d_{1 v s 2+}+d_{0 v s 1}$ and test whether it is equal to zero (i.e. effectively reversing the sign of the effect for the 1 versus $2+$ male comparison).

For an effect of female mating status, we again used Hedge's $d$ to quantify the difference in ejaculate size between males mated to non-virgin versus virgin females. The predicted effect size depends on which theoretical model is used but, in practice, most authors argue that males should allocate more sperm to mated females due to greater sperm competition (see Section II). If so, the mean effect size should be significantly positive. Female quality is a continuous variable and most studies report the regression of ejaculate size on a measure of female quality, or the correlation between the two variables. We therefore used the effect size Pearson's $r$. Where necessary we used standard equations to transform test statistics (e.g. $t, F$ or $\chi^{2}$ ) or $P$ values to $r$ (Rosenberg et al., 2000). In studies where female quality was treated as a dichotomous trait (i.e. high and low quality) and means and standard deviations for ejaculate size were available, we first calculated Cohen's $d$, which we then transformed to $r$ using $r=d /\left(d^{2}+4\right)^{1 / 2}$ (to calculate the variance in $r$ see Cooper et al., 2009, p.234). To fit parametric model assumptions, $r$ was converted to $Z_{r}$ using the Fisher transformation. The variance of $z_{r}$ is $1 /(\mathcal{N}-3)$. We predicted a positive relationship between ejaculate size and most measures of female quality, namely, female body size, body mass, sexual ornament size, condition and degree of asymmetry. We predicted a negative relationship between ejaculate size and age or infection status. Therefore, when calculating the mean effect size we reversed the sign for the effect sizes for age and infection status.

\section{(6) Publication bias}

The estimate of a mean weighted effect size is problematic if strong publication bias exists (review: Rothstein, Sutton \& Borenstein, 2009). This phenomenon has been the subject of debate among meta-analysts working on ecological and evolutionary questions (reviews: Møller \& Jennions, 2001b; Jennions et al., 2011c). The only direct method to test for publication bias is to follow a cohort of studies to see whether their effect sizes influence the likelihood, time and/or place of publication. Another fairly direct approach is to compare effect sizes between published and unpublished studies. In medicine, such surveys have shown that unpublished studies tend to have smaller effect sizes. Several recent evolutionary ecology meta-analyses have made the comparison (e.g. Jennions, Møller \& Petrie, 2001; Møller \& Jennions, 2001 a; Koricheva, 2003; Møller, Thornhill \& Gangestad, 2005) and found that the effect sizes of the two categories of studies did not differ, or that there was a counter-intuitive trend for published studies to have smaller effect sizes (Koricheva, 2003). There is, however, still concern about the ease with which unpublished studies are located (i.e. located unpublished studies might, themselves, be a biased sample of all unpublished studies). For this reason, we did not attempt to locate unpublished studies and instead we used three indirect methods to look for publication bias.

First, we calculated the Begg-Mazumdar correlation between standardized effect size and study sample size using Kendall tau rank correlation (here referred to as $\left.r_{\text {bias }}\right)$. This statistic should be interpreted with caution as it has low statistical power when $\mathcal{N}<25$ (Begg \& Mazumdar, 1994).

Second, we used 'trim and fill' (Duval \& Tweedie, 2000a,b) and the index $L$ to estimate the number of 'missing' studies based on symmetry of a funnel plot of the data (i.e. effect size versus sample size). We then recalculated the mean effect if putative 'missing' studies are included. This procedure is based on two assumptions: there should be a symmetric distribution of observed effect sizes around the 'true' effect size if publication bias is absent and the most extreme results, typically those with low sample size (high variance), have not been published. 'Trim and fill' is a form of sensitivity analysis. We performed separate analyses testing whether studies were missing for values larger or smaller than the observed mean effect.

Third, we calculated Rosenberg's fail safe number ( $\left.\mathcal{N}_{\text {Rosenberg }}\right)$, which is a statistically superior version of Rosenthal's fail-safe number (Rosenberg, 2005). It is an estimate of the number of additional studies taken from a sampling distribution with a mean centered on the null value (and the same average sample size as the located studies) required so that the reported weighted mean effect size does not differ significantly (i.e. $P>0.05$ ) from the null value (i.e. $\mathrm{r}$ or $d=0)$. Due to statistical problems that can arise when using random effect models, one must sometimes interpret $\mathcal{N}_{\text {Rosenberg }}$ as the relative size of a single additional study (i.e. its weighting relative to the average study).

To investigate temporal trends in publication we initially used Spearman rank correlation to test the strength of the relationship between date of publication and effect size. To perform an analysis that provides information on changes in the mean estimated effect size over time we performed a cumulative meta-analysis using the meta package in $R$ (Schwarzer, 2009). In a cumulative meta-analysis a series of meta-analyses are run in which effect sizes are added to the analysis in a pre-determined order - here publication date-to observe the change in the mean effect size and its variance. We added individual effect sizes by date of publication beginning with the earliest publication. 


\section{RESULTS}

The raw data and estimates of effect sizes for individual studies are provided in as online supporting information (see Section X. Appendices 1-3). Summary statistics reporting the mean effects and 95\% confidence intervals for the four meta-analyses are provided in Tables $1-4$. These tables report the mean effect size for all studies as well as those for subdivision based on type of assessment (i.e. proxy or direct), ejaculate size measure, taxon and fertilization mode. Table 5 summarizes tests for publication bias.

\section{(1) Presence of rivals}

(a) Presence of a rival male

We excluded one study (Galeotti et al., 2009) from the analyses because its effect size was an extreme outlier (see Appendix 1 and Table 1). Ejaculate size was significantly larger in the presence of a rival than without $(d=0.40$, 95\% CI: 0.15 to $0.65, \mathcal{N}=33$ species) (Table 1). There was no significant difference in effect size estimates based on direct or proxy measures of ejaculate size $\left(Q_{b}=0.015\right.$, $d . f .=1, P=0.90)$. There was also no significant effect of taxon (insects, fish, spider, mammal, bird: $Q_{b}=0.82$, d.f. $=4, P=0.94$ ) or fertilization mode (internal, external: $\left.O_{b}=0.007, d . f .=1, P=0.93\right)($ Table 1$)$.

The Begg-Mazumdar correlation was not significant $\left(r_{\text {bias }}=-0.02, P=0.75, \mathcal{N}=33\right.$ species) (Table 5). 'Trim and fill' indicated there were no studies missing. The Rosenberg fail-safe number was 494 . There was a weak but non-significant decline in effect size with year of publication $\left(r_{\mathrm{s}}=-0.279, P=0.10, \mathcal{N}=35\right)$.

\section{(b) Number of rival males (one versus more)}

We excluded one study (Galeotti et al., 2009) from the analyses because its effect size was an extreme outlier (see

Table 1. Effect size (Hedges' $d$ ) when one rival male was present on male ejaculate size calculated from studies in Appendix 1 (see Section X. Supporting information). The meta-analysis used type of assessment, sperm traits, higher taxon and fertilization mode as grouping variables. Males were predicted to donate more sperm when one rival male was present. Mean effect sizes that differed significantly from zero are in bold

\begin{tabular}{|c|c|c|c|c|c|c|}
\hline Factor & $k$ & $s$ & $m$ & $\begin{array}{l}\text { Effect size } \\
\quad d\end{array}$ & $95 \%$ CI for $d$ & $\begin{array}{c}\text { Heterogeneity } \\
Q_{\Gamma}(P, d . f .)\end{array}$ \\
\hline Pooled & $\begin{array}{r}63 \\
62^{1}\end{array}$ & $\begin{array}{r}36 \\
35^{1}\end{array}$ & $\begin{array}{r}34 \\
33^{1}\end{array}$ & $\begin{array}{c}0.404 \\
0.348^{1}\end{array}$ & $\begin{array}{l}0.154 \text { to } 0.654 \\
0.140 \text { to } 0.557^{1}\end{array}$ & $\begin{array}{c}107.19(<0.0001,33) \\
{[38.91(0.19,32)]^{1}}\end{array}$ \\
\hline $\begin{array}{l}\text { Type of assessment } \\
\text { Direct } \\
\text { Proxy }{ }^{1}\end{array}$ & $\begin{array}{l}30 \\
32\end{array}$ & $\begin{array}{l}19 \\
18\end{array}$ & $\begin{array}{l}20 \\
16\end{array}$ & $\begin{array}{l}\mathbf{0 . 6 0 1} \\
0.195\end{array}$ & $\begin{array}{c}0.342 \text { to } 0.861 \\
-0.163 \text { to } 0.552\end{array}$ & $\begin{array}{l}23.36(0.22,19) \\
20.96(0.14,15)\end{array}$ \\
\hline $\begin{array}{l}\text { Sperm traits } \\
\text { Sperm volume } \\
\text { Copulation rate } \\
\text { Copulation duration } \\
\text { Copulation number } \\
\text { Sperm number } \\
\text { Sperm area } \\
\text { Ejaculate weight } \\
\text { Ejaculate duration } \\
\text { Ejaculate rate } \\
\text { Intromission duration } \\
\text { Mounting duration } \\
\text { Number of ejaculations }\end{array}$ & $\begin{array}{r}1 \\
4 \\
11 \\
2 \\
32 \\
1 \\
6 \\
1 \\
2 \\
1 \\
1 \\
1\end{array}$ & $\begin{array}{r}1 \\
1 \\
8 \\
2 \\
20 \\
1 \\
1 \\
1 \\
2 \\
1 \\
1 \\
1\end{array}$ & $\begin{array}{r}1 \\
1 \\
8 \\
2 \\
21 \\
1 \\
1 \\
1 \\
2 \\
1 \\
1 \\
1\end{array}$ & $\begin{array}{r}-0.042 \\
-0.195 \\
0.334 \\
-0.334 \\
\mathbf{0 . 5 2 1} \\
27.158 \\
0.859 \\
-0.221 \\
0.735 \\
-0.333 \\
0.168 \\
0.896\end{array}$ & $\begin{array}{c}- \\
-0.321 \text { to } 0.990 \\
-11.421 \text { to } 10.753 \\
0.263 \text { to } 0.779 \\
- \\
- \\
-5.307 \text { to } 6.778 \\
- \\
-\end{array}$ & $\begin{array}{c}- \\
- \\
10.14(0.18,7) \\
1.00(0.32,1) \\
26.14(0.20,21) \\
- \\
- \\
1.00(0.32,1) \\
- \\
-\end{array}$ \\
\hline $\begin{array}{l}\text { Taxon } \\
\text { Reptile } \\
\text { Crustacean }\end{array}$ & $\begin{array}{r}1 \\
2 \\
1 \\
1\end{array}$ & $\begin{array}{r}1 \\
2 \\
1^{1}\end{array}$ & $\begin{array}{r}1 \\
2 \\
1^{1}\end{array}$ & $\begin{array}{l}1.322 \\
14.04 \\
1.256^{1}\end{array}$ & -150.50 to 178.590 & - \\
\hline $\begin{array}{l}\text { Bird } \\
\text { Insect } \\
\text { Fish } \\
\text { Spider } \\
\text { Mammal }\end{array}$ & $\begin{array}{r}3 \\
28 \\
14 \\
5 \\
10\end{array}$ & $\begin{array}{r}2 \\
15 \\
8 \\
2 \\
6\end{array}$ & $\begin{array}{r}2 \\
15 \\
9 \\
2 \\
3\end{array}$ & $\begin{array}{r}0.525 \\
\mathbf{0 . 4 6 5} \\
\mathbf{0 . 3 6 1} \\
-0.660 \\
-0.067\end{array}$ & $\begin{array}{c}-4.394 \text { to } 5.444 \\
0.069 \text { to } 0.860 \\
0.045 \text { to } 0.678 \\
-7.177 \text { to } 5.857 \\
-1.244 \text { to } 1.110\end{array}$ & $\begin{array}{c}1.00(0.32,1) \\
12.95(0.53,14) \\
7.91(0.44,8) \\
1.00(0.32,1) \\
2.08(0.35,2)\end{array}$ \\
\hline $\begin{array}{l}\text { Fertilization mode } \\
\text { Internal } \\
\text { External }^{1} \\
\text { Semi-internal }\end{array}$ & $\begin{array}{r}50 \\
12 \\
1\end{array}$ & $\begin{array}{r}28 \\
6 \\
1\end{array}$ & $\begin{array}{r}25 \\
7 \\
1\end{array}$ & $\begin{array}{l}0.294 \\
0.493 \\
1.256\end{array}$ & $\begin{array}{l}0.046 \text { to } 0.542 \\
0.136 \text { to } 0.849 \\
-\end{array}$ & $\begin{array}{c}31.64(0.13,24) \\
6.49(0.37,6) \\
-\end{array}$ \\
\hline
\end{tabular}

${ }^{1}$ Outlier removed: Austropotamobius italicus, $d=27.16 k=$ number of effect sizes, $s=$ number of studies, $m=$ number of species. 
Table 2. Effect sizes (Hedges' d) when more than one rival male was present on male ejaculate size calculated from studies in Appendix 1 (see Section X. Supporting information). The meta-analysis used type of assessment, sperm traits, higher taxon and fertilization mode as grouping variables. Males were predicted to donate fewer sperm when more than one rival male was present. Mean effect sizes that differed significantly from zero are in bold (i.e. $d<0$ )

\begin{tabular}{|c|c|c|c|c|c|c|}
\hline Factor & $k$ & s & $\mathrm{m}$ & $\begin{array}{c}\text { Effect size } \\
\quad d\end{array}$ & $95 \%$ CI for $d$ & $\begin{array}{c}\text { Heterogeneity } \\
\mathrm{Q}_{\mathrm{T}}(P, d . f .)\end{array}$ \\
\hline Pooled & $\begin{array}{r}22 \\
21^{1}\end{array}$ & $\begin{array}{r}14 \\
13^{1}\end{array}$ & $\begin{array}{r}16 \\
15^{1}\end{array}$ & $\begin{array}{c}0.231 \\
-0.015^{1}\end{array}$ & $\begin{array}{l}-0.227 \text { to } 0.688 \\
-0.336 \text { to } 0.305^{1}\end{array}$ & $\begin{array}{c}47.41(<0.0001,15) \\
{[17.01(0.26,14)]^{1}}\end{array}$ \\
\hline $\begin{array}{l}\text { Type of assessment } \\
\text { Direct } \\
\text { Proxy }{ }^{1}\end{array}$ & $\begin{array}{r}12 \\
9\end{array}$ & $\begin{array}{l}7 \\
7\end{array}$ & $\begin{array}{l}9 \\
7\end{array}$ & $\begin{array}{r}-0.084 \\
0.054\end{array}$ & $\begin{array}{l}-0.525 \text { to } 0.358 \\
-0.566 \text { to } 0.674\end{array}$ & $\begin{array}{l}9.75(0.28,8) \\
6.40(0.38,6)\end{array}$ \\
\hline $\begin{array}{l}\text { Sperm traits } \\
\text { Copulation duration } \\
\text { Sperm number } \\
\text { Sperm area } \\
\text { Ejaculate rate } \\
\text { Number of ejaculations }\end{array}$ & $\begin{array}{r}6 \\
13 \\
1 \\
1 \\
1\end{array}$ & $\begin{array}{l}4 \\
8 \\
1 \\
1 \\
1\end{array}$ & $\begin{array}{r}4 \\
10 \\
1 \\
1 \\
1\end{array}$ & $\begin{array}{r}0.194 \\
-0.032 \\
8.478 \\
-0.644 \\
0.058\end{array}$ & $\begin{array}{c}-1.081 \text { to } 1.469 \\
-0.401 \text { to } 0.337 \\
- \\
-\end{array}$ & $\begin{array}{c}3.45(0.33,3) \\
10.55(0.31,9) \\
- \\
- \\
-\end{array}$ \\
\hline $\begin{array}{l}\text { Taxon } \\
\text { Crustacean } \\
\text { Bird } \\
\text { Insect } \\
\text { Fish } \\
\text { Mammal }\end{array}$ & $\begin{array}{r}1 \\
2 \\
10 \\
7 \\
2\end{array}$ & $\begin{array}{l}1 \\
1 \\
6 \\
5 \\
1\end{array}$ & $\begin{array}{l}1 \\
1 \\
8 \\
5 \\
1\end{array}$ & $\begin{array}{r}8.478 \\
-0.023 \\
0.165 \\
-0.180 \\
-0.332\end{array}$ & $\begin{array}{c}- \\
-0.430 \text { to } 0.760 \\
-0.831 \text { to } 0.472 \\
-\end{array}$ & $\begin{array}{c}- \\
- \\
8.56(0.29,7) \\
4.20(0.38,4) \\
-\end{array}$ \\
\hline $\begin{array}{l}\text { Fertilization mode } \\
\text { Internal } \\
\text { External }^{1}\end{array}$ & $\begin{array}{r}15 \\
6\end{array}$ & $\begin{array}{l}9 \\
4\end{array}$ & $\begin{array}{r}11 \\
4\end{array}$ & $\begin{array}{r}0.086 \\
-0.284\end{array}$ & $\begin{array}{l}-0.321 \text { to } 0.493 \\
-1.160 \text { to } 0.593\end{array}$ & $\begin{array}{c}11.97(0.29,10) \\
3.10(0.38,3)\end{array}$ \\
\hline
\end{tabular}

${ }^{1}$ Outlier removed: Austropotamobius italicus, $d=8.48, k=$ number of effect sizes, $s=$ number of studies, $m=$ number of species.

Appendix 1 and Table 2). There was no significant effect of the number of rivals on ejaculate size $(d=-0.015,95 \%$ CI: -0.34 to $0.31, \mathcal{N}=15$ species) (Table 2 ). There was no significant difference in effect size estimates based on direct or proxy measures of ejaculate size $\left(Q_{b}=0.008\right.$, d.f. $=1, P=0.93)$. Closer inspection showed that the mean effect sizes did not differ between studies using copulation duration or sperm number $\left(Q_{b}=0.01\right.$, d.f. $\left.=1, P=0.91\right)$. There was also no significant effect of taxon (insects, fish: $\left.Q_{\mathrm{b}}=0.38, d . f .=1, P=0.59\right)$ or fertilization mode $\left(Q_{b}=0.33\right.$, d.f. $\left.=1, P=0.57\right)$ (Table 2).

The Begg-Mazumdar correlation was not significant ( $n_{\text {bias }}=0.367, P=0.051, \mathcal{N}=15$ species) (Table 5). 'Trim and fill' indicated there were no studies missing. The Rosenberg fail-safe number was 0 because the main effect size was not statistically significant. There was no significant correlation between effect size and year of publication $\left(r_{\mathrm{s}}=-0.11, P=0.72, \mathcal{N}=13\right)$.

A comparison of the effect sizes for 0 versus 1 rival and 1 versus $2+$ rivals paired by species gave a mean Cohen $q$ of 0.304 (95\% CI: -0.105 to 0.713$)(Z=0.53, P=0.57$, $\mathcal{N}=15$ species). This indicates that the two effect sizes did not differ significantly. We can also test whether the two effect sizes are equal in magnitude but opposite in direction. In this case, the mean Cohen $q$ is 0.446 (95\% CI: -0.115 to 1.007) $(Z=0.78, P=0.44, \mathcal{N}=15$ species $)$, indicating that the effect sizes are not distinguishable, despite the difference in effect size, due to the high variance associated with each estimated mean.

\section{(2) Female mating status}

Against expectations, males transferred significantly larger ejaculates to virgins than mated females $(d=-0.83,95 \%$ CI: -1.25 to $-0.43, \mathcal{N}=40$ species) (Table 3 ). There was no significant difference in effect size estimates based on direct or proxy measures of ejaculate size $\left(Q_{b}=2.36, d . f .=1\right.$, $P=0.12)$. Proxy measures indicated transfer of larger ejaculates to virgin females $(d=-1.15 ; 95 \%$ CI: -1.68 to -0.62$)$, while the mean effect is in the opposite direction but not significantly different from zero for direct measures ( $d=0.18 ; 95 \%$ CI: -0.19 to 0.54 ). Closer inspection showed that the mean effect sizes differed among studies using copulation duration, sperm number and ejaculate mass $\left(Q_{b}=18.69, d . f .=2, P<0.0001\right)$, with far more sperm transferred to virgins in studies that used copulation duration $(d=-1.33$; $95 \% \mathrm{CI}:-1.96$ to -0.69$)$ than sperm number $(d=-0.13 ; 95 \% \mathrm{CI}:-0.60$ to 0.34$)$ or ejaculate mass $(d=0.06 ; 95 \%$ CI: -1.28 to 1.39$)$. There was also a significant effect of taxon (insects, molluscs and spiders: $Q_{b}=30.55$, d.f. $\left.=2, P<0.0001\right)$, although this should be viewed with caution as the positive effect (larger ejaculates to mated females) for molluscs is based on only two studies. There was insufficient data to investigate fertilization mode (Table 3). 
Table 3. Effect sizes (Hedges' $d$ ) for the effect of female mated status on male ejaculate size calculated from studies in Appendix 2 (see Section X. Supporting information). The meta-analysis used type of assessment, sperm traits, higher taxon and fertilization mode as grouping variables. Males were predicted to donate more sperm to mated females compared with virgins so mean effect size should be greater than zero. Mean effect sizes that differed significantly from zero are in bold

\begin{tabular}{|c|c|c|c|c|c|c|}
\hline Factor & $k$ & $s$ & $m$ & $\begin{array}{l}\text { Effect size } \\
\quad d\end{array}$ & $95 \%$ CI for $d$ & $\begin{array}{l}\text { Heterogeneity } \\
\mathrm{Q}_{\mathrm{T}}(P, d . f .)\end{array}$ \\
\hline Pooled & 69 & 29 & 40 & -0.84 & $\mathbf{- 1 . 2 4 6}$ to -0.432 & $155.53(<0.0001,39)$ \\
\hline $\begin{array}{l}\text { Type of assessment } \\
\text { Direct } \\
\text { Proxy }\end{array}$ & $\begin{array}{l}20 \\
49\end{array}$ & $\begin{array}{l}12 \\
22\end{array}$ & $\begin{array}{l}12 \\
33\end{array}$ & $\begin{array}{r}0.176 \\
-\mathbf{1 . 1 5 0}\end{array}$ & $\begin{array}{l}-0.189 \text { to } 0.535 \\
-1.681 \text { to }-0.618\end{array}$ & $\begin{array}{c}10.52(0.48,11) \\
113.99(<0.0001,32)\end{array}$ \\
\hline $\begin{array}{l}\text { Sperm traits } \\
\text { Sperm volume } \\
\text { Copulation rate } \\
\text { Copulation duration } \\
\text { Sperm number } \\
\text { Sperm area } \\
\text { Ejaculate weight }\end{array}$ & $\begin{array}{r}1 \\
3 \\
37 \\
20 \\
1 \\
7\end{array}$ & $\begin{array}{r}1 \\
1 \\
18 \\
12 \\
1 \\
4\end{array}$ & $\begin{array}{r}1 \\
1 \\
29 \\
12 \\
1 \\
4\end{array}$ & $\begin{array}{r}1.477 \\
-0.919 \\
-1.326 \\
-0.129 \\
0.179 \\
0.055\end{array}$ & $\begin{array}{c}- \\
-1.964 \text { to }-0.688 \\
-0.599 \text { to } 0.341 \\
-1.282 \text { to } 1.392\end{array}$ & $\begin{array}{c}- \\
- \\
92.77(<0.0001,28) \\
45.16(<0.0001,11) \\
2.81(0.42,3)\end{array}$ \\
\hline $\begin{array}{l}\text { Taxon } \\
\text { Acarid } \\
\text { Crustacean } \\
\text { Insect } \\
\text { Mollusc } \\
\text { Oligochaete } \\
\text { Spider }\end{array}$ & $\begin{array}{r}1 \\
2 \\
51 \\
2 \\
1 \\
12\end{array}$ & $\begin{array}{r}1 \\
1 \\
18 \\
2 \\
1 \\
6\end{array}$ & $\begin{array}{r}1 \\
1 \\
29 \\
2 \\
1 \\
6\end{array}$ & $\begin{array}{r}-3.799 \\
0.004 \\
-\mathbf{0 . 8 5 5} \\
0.533 \\
1.477 \\
-0.890\end{array}$ & $\begin{array}{c}- \\
-1.275 \text { to }-0.435 \\
-7.192 \text { to } 8.258 \\
-2.468 \text { to } 0.689\end{array}$ & $\begin{array}{c}- \\
-\overline{-} \\
171.99(<0.0001,28) \\
1.00(0.32,1) \\
\quad- \\
3.46(0.63,5)\end{array}$ \\
\hline $\begin{array}{l}\text { Fertilization mode } \\
\text { Internal } \\
\text { External }\end{array}$ & $\begin{array}{r}67 \\
2\end{array}$ & $\begin{array}{r}28 \\
1\end{array}$ & $\begin{array}{r}39 \\
1\end{array}$ & $\begin{array}{r}-\mathbf{0 . 8 6 2} \\
0.004\end{array}$ & $\begin{array}{c}-1.275 \text { to }-0.448 \\
-\end{array}$ & $154.18(<0.0001,38)$ \\
\hline
\end{tabular}

$k=$ number of effect sizes, $s=$ number of studies, $m=$ number of species.

The Begg-Mazumdar correlation was marginally significant $\left(r_{\text {bias }}=-0.221, P=0.05, \mathcal{N}=40\right.$ species) (Table 5). 'Trim and fill' indicated there were no studies missing when looking for studies with a more positive effect size than that observed, but eight studies missing when looking for studies with a more negative effect size than that observed. This led to a revised estimate of the mean effect of $d=-1.39(95 \%$ CI: -1.89 to -0.90$)$. This reinforced the observed trend for larger ejaculate size when mating with virgin females. The Rosenberg fail-safe number was 123 . There was no significant correlation between effect size and year of publication $\left(r_{\mathrm{s}}=0.16, P=0.41, \mathcal{N}=29\right)$.

\section{(3) Female quality}

Males transferred significantly larger ejaculates to higher quality females $(r=0.311,95 \%$ CI: $0.21-0.41, \mathcal{N}=40$ species) (Table 4). There was no significant difference between effect size estimates based on direct or proxy measures of ejaculate size $\left(Q_{b}=0.014, d . f .=1, P=0.91\right)$ or among estimates based on the female traits of age, size and mass $\left(Q_{b}=3.79, d . f .=2, P=0.15\right)$. However, effect sizes differed among molluscs, spiders, crustaceans and insects $\left(Q_{b}=9.29, d . f .=3, P=0.02\right)$, with a far higher value for crustaceans than insects $(r=0.58$ versus 0.17$)$. There was also a difference between fertilization modes, being higher for semi-internal than internal fertilizers $\left(Q_{b}=4.91, d . f .=1\right.$, $P=0.03)$ (Table 4).
The Begg-Mazumdar correlation was not significantly different from zero $\left(r_{\text {bias }}=-0.081, P=0.46, \mathcal{N}=40\right.$ species $)$ (Table 5). 'Trim and fill' indicated there were no studies missing when looking for studies with a smaller effect size than that observed; two studies were missing when looking for studies with a larger effect size than that observed. This led to a revised estimate of the mean effect that was slightly higher at $r=0.357$ (95\% CI: 0.25 to 0.47$)$. The Rosenberg fail-safe number was 3308. There was no significant correlation between effect size and year of publication $\left(r_{\mathrm{s}}=0.155, P=0.30, \mathcal{N}=46\right)$. There was therefore little indirect evidence for publication bias (Table 5).

\section{DISGUSSION}

The theoretical prediction that a greater risk of sperm competition, as indicated by the presence of a rival male, leads to the transfer of more sperm is well supported (Section II). This finding was robust to whether the analysis was based on a direct sperm count or the use of proxy measures. There was no effect of taxon or fertilization mode, although this result should be viewed with caution as the sample size is modest (34 species) so statistical power is limited. It is noteworthy that a cumulative meta-analysis shows that the mean effect has been significant since 2000 (Fig. 1). By contrast, the prediction that ejaculate size will decrease 
Table 4. Effect sizes (Pearson's $r$ ) for the effect of female quality on male ejaculate size calculated from studies in Appendix 3 (see Section X. Supporting information). The meta-analysis used type of assessment, female trait, higher taxon and fertilization mode (predicted direction of effect) as grouping variables. Mean effect sizes that differed significantly from zero are in bold

\begin{tabular}{|c|c|c|c|c|c|c|c|}
\hline Factor & $k$ & $s$ & $m$ & $n$ & $\begin{array}{l}\text { Effect size } \\
\quad r(\mathrm{Zr})\end{array}$ & $\begin{array}{c}95 \% \text { CI for } r \\
(95 \% \text { CI for } \mathrm{Zr})\end{array}$ & $\begin{array}{c}\text { Heterogeneity } \\
\mathrm{Q}_{\mathrm{T}}(P, d . f .)\end{array}$ \\
\hline Pooled $^{1}$ & 89 & 46 & 40 & 4551 & $0.315(0.327)$ & $\begin{array}{c}0.209 \text { to } 0.415 \\
(0.212 \text { to } 0.441)\end{array}$ & $45.01(0.23,39)$ \\
\hline \multicolumn{8}{|c|}{ Type of assessment } \\
\hline Direct ${ }^{1}$ & 50 & 30 & 26 & 2075 & $0.272(0.280)$ & $\begin{array}{c}0.158 \text { to } 0.379 \\
(0.159 \text { to } 0.399)\end{array}$ & $31.89(0.16,25)$ \\
\hline $\operatorname{Proxy}^{1}$ & 39 & 21 & 20 & 2612 & $0.293(0.302)$ & $\begin{array}{c}0.115 \text { to } 0.452 \\
(0.116 \text { to } 0.487)\end{array}$ & $21.65(0.30,19)$ \\
\hline \multicolumn{8}{|l|}{ Female traits } \\
\hline Age (-) & 13 & 7 & 7 & 369 & $0.122(0.123)$ & $\begin{array}{l}-0.167 \text { to } 0.392 \\
(-0.168 \text { to } 0.414)\end{array}$ & $7.12(0.31,6)$ \\
\hline Size $(+)$ & 49 & 28 & 27 & 2797 & $0.356(0.372)$ & $\begin{array}{l}0.210 \text { to } 0.486 \\
(0.213 \text { to } 0.531)\end{array}$ & $27.82(0.37,26)$ \\
\hline Asymmetry (+) & 2 & 2 & 2 & 100 & $0.472(0.513)$ & - & - \\
\hline Weight $(+)$ & 16 & 10 & 10 & 758 & $0.144(0.145)$ & $\begin{array}{l}-0.004 \text { to } 0.287 \\
(-0.004 \text { to } 0.295)\end{array}$ & $10.55(0.30,9)$ \\
\hline Condition $(+)$ & 1 & 1 & 1 & 65 & $0.544(0.610)$ & - & - \\
\hline Infection $(-)$ & 1 & 1 & 1 & 20 & $0.524(0.582)$ & - & - \\
\hline Relatedness (-) & 1 & 1 & 1 & 14 & $-0.514(0.568)$ & - & - \\
\hline Comb size $(+)$ & 6 & 3 & 1 & 267 & $0.320(0.332)$ & - & - \\
\hline \multicolumn{8}{|l|}{ Taxon } \\
\hline Bird & 6 & 3 & 1 & 267 & $0.320(0.332)$ & - & - \\
\hline Crustacean & 16 & 8 & 7 & 900 & $0.579(0.661)$ & $\begin{array}{l}0.110 \text { to } 0.837 \\
(0.110 \text { to } 1.211)\end{array}$ & $3.28(0.77,6)$ \\
\hline Fish & 1 & 1 & 1 & 14 & $0.640(0.758)$ & - & - \\
\hline Insect & 46 & 27 & 24 & 2736 & $0.175(0.177)$ & $\begin{array}{c}0.073 \text { to } 0.274 \\
(0.073 \text { to } 0.281)\end{array}$ & $35.34(0.048,23)$ \\
\hline Mollusc & 7 & 4 & 4 & 272 & $0.407(0.432)$ & $\begin{array}{l}-0.182 \text { to } 0.781 \\
(-0.184 \text { to } 1.048)\end{array}$ & $3.43(0.33,3)$ \\
\hline Oligochaete & 2 & 2 & 1 & 28 & $0.416(0.443)$ & - & - \\
\hline Spider & 11 & 2 & 2 & 470 & $0.244(0.249)$ & $\begin{array}{l}-0.996 \text { to } 0.998 \\
(-3.095 \text { to } 3.594)\end{array}$ & $1.00(0.32,1)$ \\
\hline \multicolumn{8}{|c|}{ Fertilization mode } \\
\hline Internal & 79 & 40 & 35 & 4375 & $0.275(0.283)$ & $\begin{array}{c}0.160 \text { to } 0.382 \\
(0.162 \text { to } 0.402)\end{array}$ & $39.99(0.22,34)$ \\
\hline External & 2 & 1 & 1 & 135 & $0.332(0.0345)$ & 0.10200 .104 & - \\
\hline Semi-internal & 8 & 5 & 4 & 177 & $0.623(0.731)$ & $\begin{array}{c}0.278 \text { to } 0.826 \\
(0.286 \text { to } 1.176)\end{array}$ & $2.78(0.43,3)$ \\
\hline
\end{tabular}

${ }^{1}$ using sign-reversed effect sizes.

$k=$ number of effect sizes, $s=$ number of studies, $m=$ number of species, $n=$ number of observations.

with the intensity of sperm competition, as assessed based on the number of rivals present prior to mating, was not supported. The sample size is, however, again quite small at 15 species. Even so, the mean effect was very close to zero, there was little evidence for even a trend in the predicted direction and the cumulative meta-analysis suggests that there is no temporal trend in the predicted direction (Fig. 2). The analysis seemed to be robust to whether it was based on a direct sperm count or a proxy measure of ejaculate size. This finding suggests that authors should be circumspect when claiming that strategic ejaculation occurs in response to the intensity of sperm competition. At present the data do not support this claim. More studies using species in which males regularly encounter natural situations where the intensity of sperm competition varies are needed to provide the strongest possible test of this theoretical prediction.

Our results were even more intriguing for the effect of female mating status. Most authors assume that ejaculate size will be larger when mating with a previously mated than with a virgin female. Theory predicts that the opposite pattern is also possible (Section II). We found a clear pattern for males to transfer significantly larger ejaculates to virgin females. A cumulative meta-analysis shows that the mean effect has been marginally significant since 1998 and has remained fairly constant (Fig. 3). The mean effect size depended, however, on whether the study used a direct sperm count or proxy measure of ejaculate size. This is mainly because males copulated for longer with virgin females. Looking only at studies 
Table 5. Species-level number of 'missing studies' with corrected effect size as calculated by trim and fill. Begg-Mazumdar correlation between species-level standardized effect size and sample size $\left(\eta_{\text {bias }}\right)$ and correlation between study-level effect size and publication year. Effect size is given as $\mathrm{Zr}$ for female quality and Hedges' $d$ for female status and male rivalry. $m=$ number of effect sizes at species level, $s=$ number of effect sizes at study level, $\mathcal{N}=$ number of missing studies

\begin{tabular}{|c|c|c|c|c|c|c|c|}
\hline Factor & $m$ & $\mathcal{N}$ & $\begin{array}{l}\text { Corrected } \\
\text { effect size }\end{array}$ & $\begin{array}{l}\text { Corrected } 95 \% \\
\text { CI }\end{array}$ & $r_{\text {bias }}(P)$ & $\mathrm{s}$ & $\begin{array}{l}\text { Effect size vs } \\
\text { year }(P)\end{array}$ \\
\hline Male rivals & 34 & $0^{\mathrm{P}}$ & \multirow[t]{2}{*}{$\mathrm{n} / \mathrm{a}$} & \multirow[t]{2}{*}{$\mathrm{n} / \mathrm{a}$} & $-0.041(0.75)$ & 36 & $-0.186(0.28)$ \\
\hline (0 versus 1$)$ & $33^{1}$ & $0^{\mathrm{N}}$ & & & $-0.019(0.89)$ & $35^{1}$ & $-0.279(0.10)^{1}$ \\
\hline Male rivals & 16 & $0^{\mathrm{P}}$ & \multirow[t]{2}{*}{$\mathrm{n} / \mathrm{a}$} & \multirow[t]{2}{*}{$\mathrm{n} / \mathrm{a}$} & $0.276(0.17)$ & 14 & $0.020(0.95)$ \\
\hline (1 versus many) & $15^{2}$ & $0^{\mathrm{N}}$ & & & $0.367(0.051)$ & $13^{2}$ & $-0.111(0.72)^{2}$ \\
\hline \multirow[t]{2}{*}{ Female status } & \multirow[t]{2}{*}{40} & $0^{\mathrm{P}}$ & $\mathrm{n} / \mathrm{a}$ & $\mathrm{n} / \mathrm{a}$ & \multirow[t]{2}{*}{$-0.221(0.05)$} & \multirow[t]{2}{*}{29} & \multirow[t]{2}{*}{$0.16(0.41)$} \\
\hline & & $8^{\mathrm{N}}$ & -1.394 & $(-1.894$ to -0.895$)$ & & & \\
\hline \multirow[t]{2}{*}{ Female quality } & \multirow[t]{2}{*}{40} & $0^{\mathrm{P}}$ & $\mathrm{n} / \mathrm{a}$ & $\mathrm{n} / \mathrm{a}$ & \multirow[t]{2}{*}{$-0.081(0.46)$} & \multirow[t]{2}{*}{46} & \multirow[t]{2}{*}{$0.155(0.30)$} \\
\hline & & $2^{\mathrm{N}}$ & 0.357 & $(0.2426$ to 0.4711$)$ & & & \\
\hline
\end{tabular}

${ }^{1}$ Outlier removed: Austropotamobius italicus, $d=27.15$.

${ }^{2}$ Outlier removed: Austropotamobius italicus, $d=8.48$.

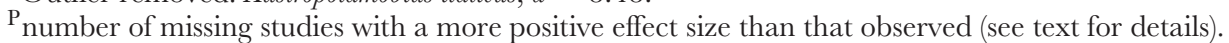

$\mathrm{N}$ number of missing studies with a more negative effect size than that observed (see text for details).

using direct sperm counts shows that the mean effect size did not differ from zero, although this result is based on only 12 species. Interpreting the results of this meta-analysis is challenging. It might be possible, if enough is known about the breeding biology of the study species, to separate studies into those that predict relatively larger or smaller ejaculate size for virgin females and then conducting separate meta-analyses. What is clear, however, is that it is currently inappropriate for authors to claim that strategic ejaculation in response to female mating status is well documented in the absence of strong predictions that are appropriate for the species in question. It is also important that the extent to which copulation duration predicts ejaculate size is re-examined, as copulation duration can vary for reasons other than those related to the transfer of more sperm (Simmons, 2001).

Finally, as predicted, we found that males transferred significantly larger ejaculates to higher quality females. A cumulative analysis shows that the mean has been significant since 1994 and, after some initial shifts, has remained extremely constant (Fig. 4). Our findings were robust to whether the analysis was based on a direct sperm count or the use of proxy measures. There was also a taxon effect which was driven by a far higher value for crustaceans than insects. This effect size difference might reflect a difference in the reproductive biology of these two taxa (e.g. perhaps highquality females are rare in crustaceans and so warrant greater sperm investment when found). Alternatively, it might reflect a methodological effect due to the relative ease with which ejaculate size is estimated in the two taxa (sperm are often deposited on the body of Crustaceans rather than internally). Greater measurement accuracy results in smaller standard deviations, thus increasing the value of standardized effect sizes. Support for this interpretation comes from the fact that the effect size was higher for species that deposited sperm on the outside of the female rather than internally. There are currently too few data to separate the effect of taxon and fertilization mode.
In general, there was little evidence for a publication bias. Only one of the four Begg-Mazumdar correlations was significant (at $P=0.04$ ). There was no evidence for a temporal increase or decrease in effect size values. The correlation ranged between -0.310 and 0.174 . 'Trim and fill' generally indicated very few missing studies. In the one case where it did the observed result was strengthened. The cumulative meta-analyses also showed few major changes in the mean effect, and no temporal shifts in the direction of the mean effect.

\section{CONGLUSIONS AND FUTURE DIREGTIONS}

(1) We found that some theoretical predictions about strategic ejaculation are well supported, but there is currently little support for others. This suggests that there are unresolved issues in determining when and how specific sperm traits are sexually selected. We simply do not have enough data to test many of the theoretical models that are currently described in the literature as being well supported. The evidence is not there, and our conclusions are less confirmatory than those in an earlier, widely-cited narrative review (Wedell et al., 2002). The lack of support for theory does not mean that the current sperm competition models are internally flawed (i.e. illogical). Theoretical models make assumptions about, for example, the ability of males to acquire information, the ability of males to assess competitor numbers and the effectiveness of selection to produce the predicted phenotypic plasticity in ejaculate size (Parker \& Pizzari, 2010, p.925, 928). If these assumptions do not hold in nature then the predicted outcomes might not arise.

(2) The extent to which theory predicts the observed effect sizes in experiments that test for an ejaculate size difference between ' 0 versus 1 rival' set-ups and ' 1 versus several rivals' set-ups should be considered carefully. Engqvist \& Reinhold 
YEAR

1990

1991

1991

1995

1996

1998

2001

2001

2001

2002

2002

2002

2003

2003

2003

2003

2003

2004

2004

2004

2005

2006

2006

2006

2006

2007

2007

2007

2007

2007

2008

2008

2009

2009

2009

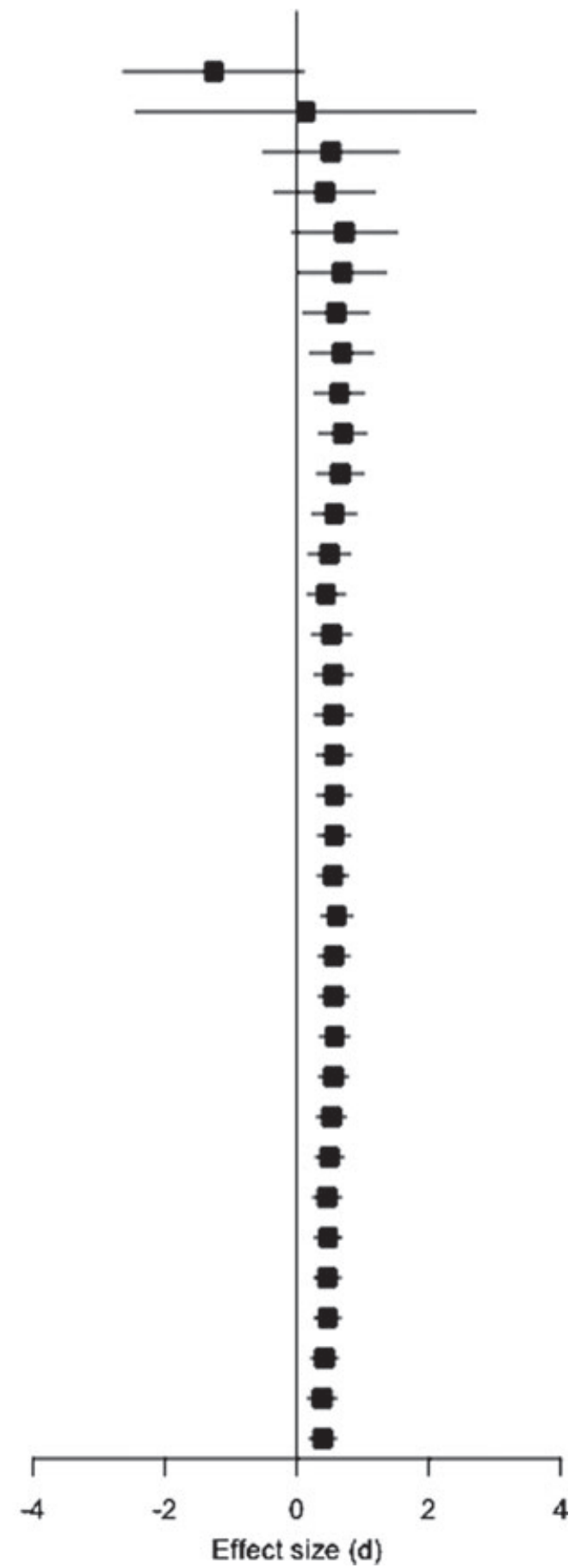

Fig. 1. Temporal changes in reported effect sizes (Hedges' $d$ ) for the effect of the presence of one rival male on focal male ejaculate size for $\mathcal{N}=35$ studies spanning the years 1990-2009. The outlying effect size $d=27.16$ for Austropotamobius italicus (Galeotti et al., 2009) was removed.

(2005) make the case that a major problem with 'male rival' experiments is that they might alter the focal male's perception of both the future mean and the immediate level of sperm competition. The extent to which they affect a male's perception of the immediate risk versus intensity of

YEAR
1998
2001
2002
2002
2003
2004
2005
2006
2006
2006
2007
2009
2009

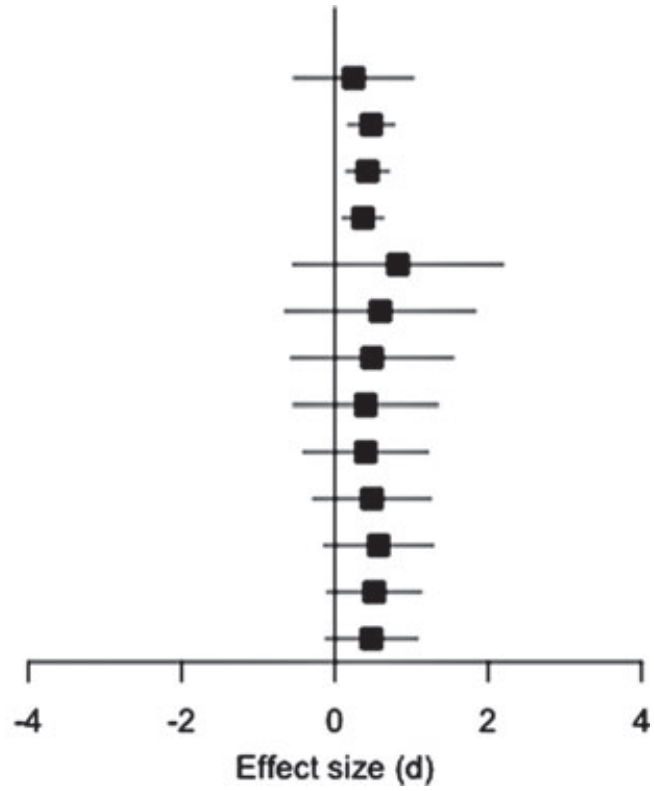

Fig. 2. Temporal changes in reported effect sizes (Hedges' $d$ ) for the effect of the presence of more than one rival male on focal male ejaculate size for $\mathcal{N}=13$ studies spanning the years 1998-2009. The outlying effect size $d=8.48$ for Austropotamobius italicus (Galeotti et al., 2009) was removed.

sperm competition is also unclear. This makes it challenging to interpret the results. For example, the positive effect size for the 0 versus 1 comparison could be described as evidence for strategic ejaculation in response to the immediate risk of sperm competition. However, it might also reflect the first response in a longer term shift towards greater investment in ejaculates due to an increase in the perceived future mean risk or intensity of sperm competition.

(3) Additional models of strategic ejaculation might be needed. Recent models by Williams et al. (2005) and Fromhage et al. (2008) represent a shift from earlier models because they do not fix the level of sperm competition (mean or variance) and instead allow it to evolve as ejaculate size changes. The model of Tazzyman et al. (2009) also expands on earlier models by allowing for continuous variation among males in the resources they invest into reproduction, and the costs of obtaining a mating. These models are, however, all 'species'-level models that do not make explicit predictions about variation in the risk/intensity of sperm competition or difference in female fecundity among mating opportunities. Given previous misunderstanding about when predictions apply within and across species, it would be useful to modify these models and apply them to strategic ejaculation with respect to ejaculate size.

(4) Phenotypic plasticity models are needed that consider the relative costs and probability of misclassification of a mating event (i.e. type I and type II errors). There is also a need to include the trade-off between the benefits of obtaining a more precise estimate of the likely levels of sperm competition for a given mating and the costs of developing/maintaining the relevant sensory mechanisms. 


\begin{tabular}{l} 
YEAR \\
1975 \\
1990 \\
1992 \\
1993 \\
1993 \\
1994 \\
1995 \\
1998 \\
1998 \\
1998 \\
1999 \\
2001 \\
2001 \\
2002 \\
2003 \\
2003 \\
2004 \\
2004 \\
2004 \\
2005 \\
2005 \\
2005 \\
2006 \\
2006 \\
2007 \\
2007 \\
2007 \\
2008 \\
2008 \\
\hline
\end{tabular}

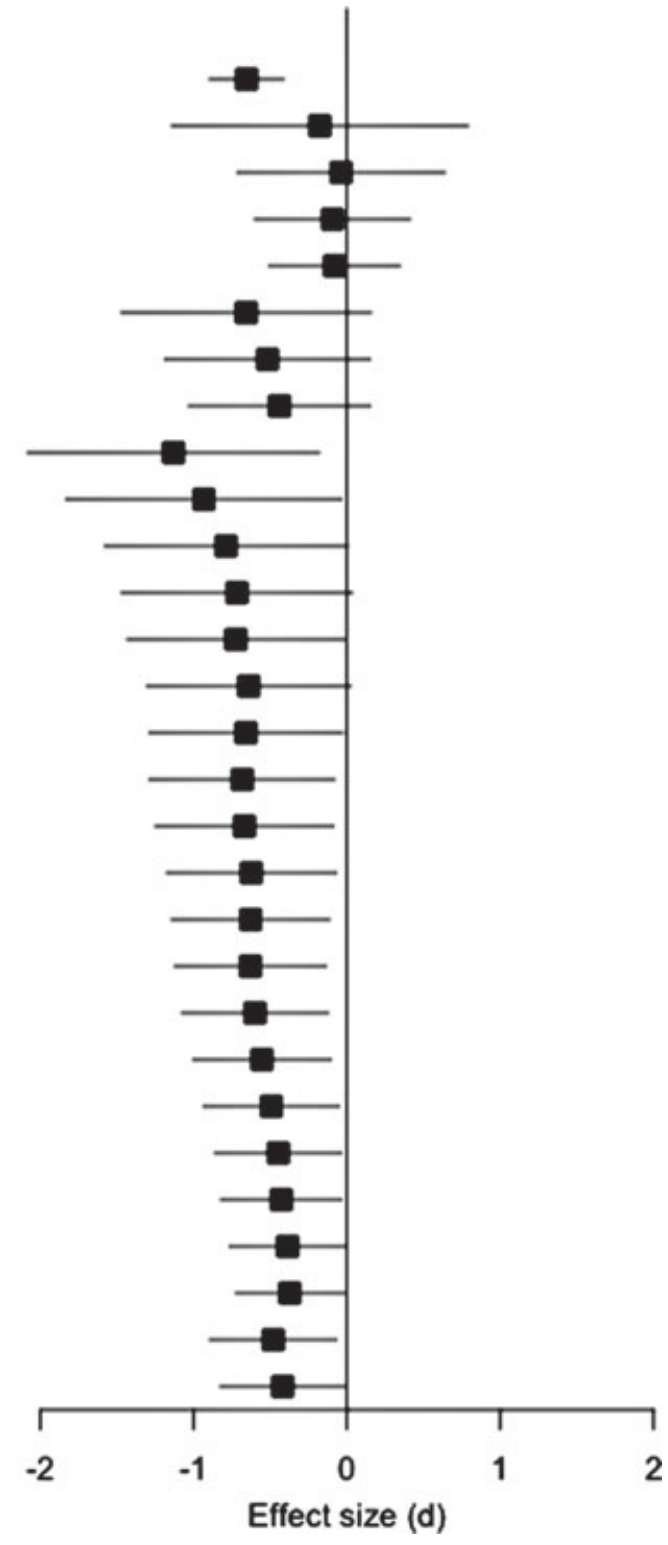

Fig. 3. Temporal changes in reported effect sizes (Hedges' $d$ ) for the effect of female mated status (virgin versus mated) on focal male ejaculate size for $\mathcal{N}=29$ studies spanning the years 1975-2008.

There are presumably costs associated with the physiological task of adjusting ejaculate size. Current game theory models simply ask what males should do if they have information about, for example, female mating status or how many rival males might release sperm. They do not explicitly consider these hidden costs, identification of which will require greater understanding of proximate mechanisms. These costs will sometimes make strategic sperm allocation maladaptive for the same reasons that organisms do not show high phenotypic plasticity in every trait, even if this sometimes leads to suboptimal trait expression under some conditions.

(5) An issue of ongoing concern is how to quantify the risk and intensity of sperm competition, or whether this is

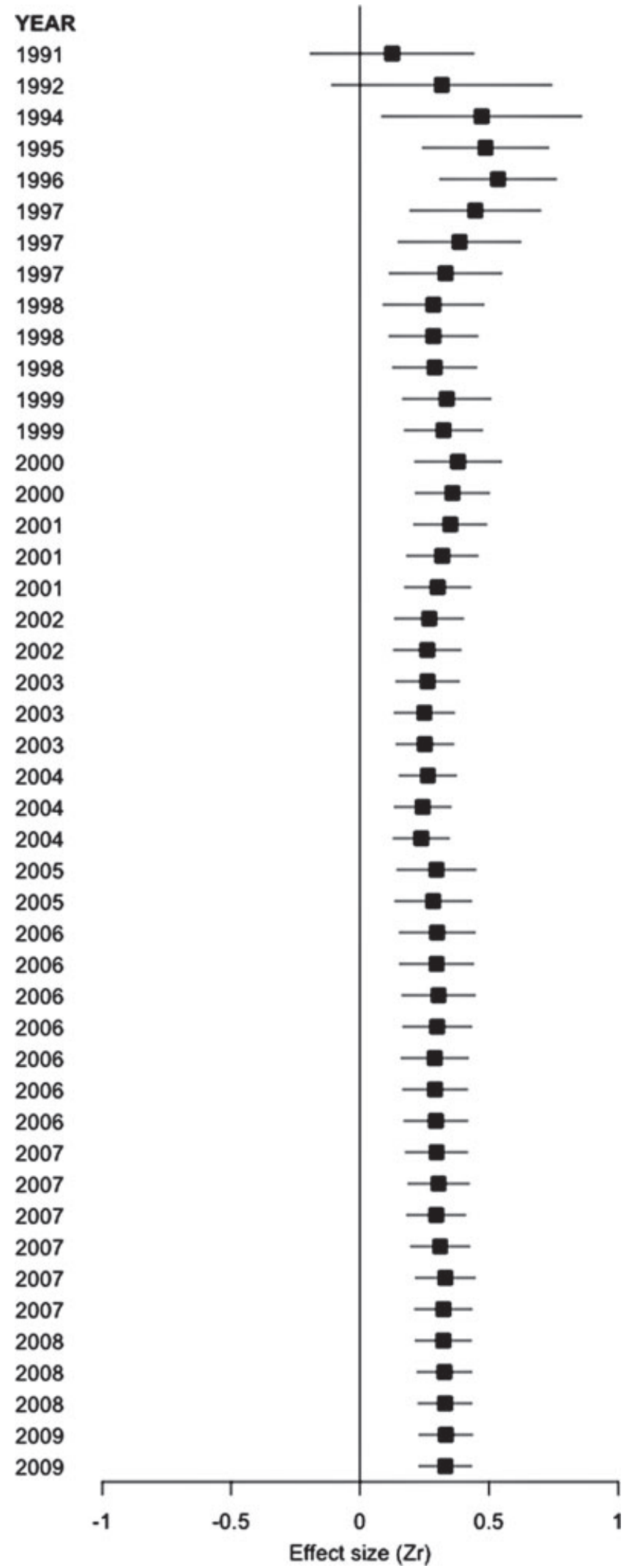

Fig. 4. Temporal changes in reported effect sizes (Hedges' $d$ ) for the effect of female quality on focal male ejaculate size for $\mathcal{N}=46$ studies spanning the years 1991-2009. 
even sensible when the mean and variance in female mating levels covary (Williams et al., 2005). A recent theoretical paper on marine external fertilizers illustrates the confusion that surrounds the problems of distinguishing risk and intensity of sperm competition and distinguishing between predictions about ejaculate expenditure and ejaculate size. In broadcast-spawning marine invertebrates, eggs can fail to hatch due to either sperm limitation (due to dilution effects) or because they encounter too many sperm (polyspermy) (review: Levitan, 2010). Bode \& Marshall (2007) produced a game theory model predicting selection for smaller ejaculate size as the average number of competing males increased. They described this prediction as being in the opposite direction to that derived for internal fertilizers, claiming that previous models predict 'when sperm competition is likely, males should generally release more of their sperm but less frequently to better compete'. This implies that ejaculate size should be larger when sperm competition is higher. This statement is true when referring to models based on the risk of sperm competition, but not those related to its intensity (Parker \& Ball, 2005). It is also true when thinking in terms of relative expenditure on ejaculates at the cross-species level.

(6) Some of our findings contradicted widespread expectations. One response is that different mating systems or species require that different assumptions (hence theoretical models) are used and that we have inappropriately pooled studies where there was no single prediction. For example, we show that males seem to provide more sperm to virgins rather than mated females (or that there is no effect). This outcome is actually compatible with theory given certain assumptions (e.g. Ball \& Parker, 2007), but so is the reverse pattern (Parker et al., 1997; see also Wedell et al., 2002). In practice, however, most researchers 'prefer' the prediction that males will transfer more sperm to mated females: this is definitely the statement most often encountered when reading general accounts of strategic ejaculation (e.g. Simmons et al. 1993; Martin \& Hosken, 2002; Bateman \& Ferguson, 2004 Velando, Eiroa \& Dominguez, 2008). Given that researchers cite studies as supporting theory when they produce a result in the desired direction (without checking whether the underlying assumptions are supported), we feel justified for now in taking the 'general prediction' at face value and pointing out that it is not supported. Clearly, better practice is to devise species-appropriate predictions, test them and then conduct a meta-analysis to see if there is a systematic bias in a given direction away from the predicted response. This would, however, require far more intensive data collection than is currently possible given the pressure continually to test 'novel' hypotheses, rather than robustly confirm or refute established ones (Kelly, 2006; Jennions et al., 2011 b).

(7) We often encountered miscitation of studies in the strategic ejaculation literature. Several studies that were cited as supporting this phenomenon, upon closer examination (i.e. when extracting effect sizes), revealed that the evidence was weak or inconclusive. There is obviously positive feedback in how papers are cited when one accepts previous citation usage at face value. In our view, meta-analysis offers the best solution to the problem. If a study does not yield an effect size, it probably does not contain the relevant data (or if it does the way in which the data are presented is such that it has to be discounted). Conversely, if it does yield an effect size then one can state numerically how strong the effect actually is (which is not equivalent to basing claims on $P$ values, as effect sizes also depend on the sample size).

\section{AGKNOWLEDGEMENTS}

We thank Dean Adams for assistance in running analyses in $R$ and M. Thomas, T. Jones, A. Bretman, P. Galeotti, M. Schaefer, M. Siva-Jothy and D. Droney for generously providing summary statistics unavailable in their published work. We thank students, friends and spouses for tolerating the many extra hours spent in the office. Funding was provided by the Australian Research Council, the A.N.U. Faculty of Science and Iowa State University.

\section{REFERENCES}

References marked with * were used in the meta-analyses

Adams, D. C. (2008). Phylogenetic meta-analysis. Evolution 62, 567-572.

*Aisenberg, A., Estramil, N., Toscano-Gadea, C. \& Gonzalez, M. (2009). Timing of female sexual unreceptivity and male adjustment of copulatory behaviour under competition risk in the wolf spider Schizocosa malitiosa. Journal of Ethology 27, $43-50$.

Alonzo, S. H. \& WARner, R. R. (2000). Allocation to mate guarding or increased sperm production in a Mediterranean wrasse. American Naturalist 156, 266-275.

*Alonso-Pimentel, H. \& PAPAJ, D. R. (1996). Operational sex ratio versus gender density as determinants of copulation duration in the walnut fly, Rhagoletis juglandis (Diptera: Tephritidae). Behavioral Ecology and Sociobiology 39, 171-180.

*Anthes, N., Putz, A. \& Michiels, N. K. (2006). Hermaphrodite sex role preferences: The role of partner body size, mating history and female fitness in the sea slug Chelidonura sandrana. Behavioral Ecology and Sociobiology 60, 359-367.

Archer, M. S. \& Elgar, M. A. (1999). Female preference for multiple partners: sperm competition in the hide beetle, Dermestes maculatus (DeGeer). Animal Behaviour 58, 669-675.

Arnovist, G., Edvardsson, M., Friberg, U. \& Nilsson, T. (2000). Sexual conflict promotes speciation in insects. Proceedings of the National Academy of Sciences USA 97, $10460-10464$.

*Aspbury, A. S. (2007). Sperm Competition effects on sperm production and expenditure in sailfin mollies, Poecilia latipinna. Behavioral Ecology 18, 776-780.

*Aspbury, A. S. \& Gabor, C. R. (2004). Discriminating males alter sperm production between species. Proceedings of the National Academy of Sciences USA 101, 15970-15973.

Awata, S., Heg, D., Munehara, H. \& Kohda, M. (2006). Testis size depends on social status and the presence of male helpers in the cooperatively breeding cichlid Julidochromis ornatus. Behavioral Ecology 17, 372-379.

Awata, S., Takeyama, T., Makino, Y., Kitamura, Y. \& Kohda, M. (2008), Cooperatively breeding cichlid fish adjust their testis size but not sperm traits in relation to sperm competition risk. Behavioral Ecology and Sociobiology 62, 1701-1710.

BAKER, R. \& JACKSON, D. (2006). Using journal impact factors to correct for the publication bias of medical studies. Biometrics 62, 785-792.

BAKer, R. R. \& Bellis, M. A. (1989). Number of sperm in human ejaculates varies in accordance with sperm competition theory. Animal Behaviour 37, 867-869.

Ball, M. A. \& PARker, G. A. (1998). Sperm competition games: a general approach to risk assessment. Fournal of Theoretical Biology 194, 251-262.

Ball, M. A. \& Parker, G. A. (2007). Sperm competition games: the risk model can generate higher sperm allocation to virgin females. Fournal of Evolutionary Biology 20, $767-779$.

Bateman, P. W. (1998). Mate preference for novel partners in the cricket Gryllus bimaculatus. Ecological Entomology 23, 473-475.

*Bateman, P. W. \& Ferguson, J. W. H. (2004). Male mate choice in the botswana armoured ground cricket Acanthoplus discoidalis (Orthoptera: Tettigoniidae: Hetrodinae). Can, and how, do males judge female mating history? Fournal of Zoology 262,305-309. 
*Bateman, P. W., Gilson, L. N. \& Ferguson, J. W. H. (2001). Investment in mate guarding may compensate for constraints on ejaculate production in the cricket Gryllodes sigillatus. Ethology 107, 1087-1098.

*Baur, B., Locher, R. \& Baur, A. (1998). Sperm allocation in the simultaneously hermaphroditic land snail Arianta arbustorum. Animal Behaviour 56, 839-845.

Bates, D.M. \& Pinheiro, J.C. (2002). Mixed Effects Models in S and S-Plus. Springer, New York.

BegG, C. B. \& Mazumdar, M. (1994). Operating characteristics of a rank correlation test for publication bias. Biometrics 50, 1088-1101.

*Bellis, M., Baker, R. \& Gage, M. (1990). Variation in rat ejaculates consistent with the kamikaze-sperm hypothesis. Fournal of Mammalogy 71, 479-480.

Bjork, A., Dallai, R. \& Pitnick, S. (2007). Adaptive modulation of sperm production rate in Drosophila bifurca, a species with giant sperm. Biology Letters 3, $517-519$.

BJÖRKLUND, M. (1997). Are 'comparative methods' always necessary? Oikos 80, $607-612$.

Bode, M. \& Marshall, D. J. (2007). The quick and the dead? Sperm competition and sexual conflict in sea. Evolution 61, 2693-2700.

Bonduriansky, R. (2001). The evolution of male mate choice in insects: a synthesis of ideas and evidence. Biological Reviewes 76, 305-339.

Borenstein, M., Hedges, L. V., Higgins, J. P. T. \& Rothstein, H. R. (2009). Introduction to Meta-analysis. John Wiley \& Sons, New York.

*Bretman, A., Fricke, C. \& Chapman, T. (2009). Plastic responses of male Drosophila melanogaster to the level of sperm competition increase male reproductive fitness. Proceedings of the Royal Society of London Series B-Biological Sciences 276, 1705-1711.

*Brockerhoff, A. M. \& Mclay, C. L. (2005). Mating behaviour, female receptivity and male-male competition in the intertidal crab Hemigrapsus sexdentatus (Brachyura: Grapsidae). Marine Ecology Progress Series 290, 179-191.

*Bukowski, T. C., Linn, C. D. \& Christenson, T. E. (2001). Copulation and sperm release in Gasteracantha cancriformis (Araneae: Araneidae): Differential male behaviour based on female mating history. Animal Behaviour 62, 887-895.

Cameron, E., Day, T. \& Rowe, L. (2007). Sperm competition and the evolution of ejaculate composition. American Naturalist 169, E158-E172.

*Candolin, U. \& Reynolds, J. D. (2002). Adjustments of ejaculation rates in response to risk of sperm competition in a fish, the bitterling (Rhodeus sericeus). Proceedings of the Royal Society of London Series B-Biological Sciences 269, 1549-1553.

*Carazo, P., Font, E. \& Alfthan, B. (2007). Chemosensory assessment of sperm competition levels and the evolution of internal spermatophore guarding. Proceedings of the Royal Society of London Series B-Biological Sciences 274, 261-267.

*CoOK, P. \& GAGE, M. (1995). Effects of risks of sperm competition on the numbers of eupyrene and apyrene sperm ejaculated by the moth Plodia interpunctella (Lepidoptera, Pyralidae). Behavioral Ecology and Sociobiology 36, 261-268.

Cooper, H. M., Hedges, L. V. \& Valentine, J. C. (eds.) (2009). The Handbook of Research Synthesis and Meta-analysis, $2^{\text {nd }}$ Edition. Russell Sage, New York.

*Cordero, A. \& Miller, P. (1992). Sperm transfer, displacement and precedence in Ischmura graellsii (Odonata, Coenagrionidae). Behavioral Ecology and Sociobiology 30, $261-267$.

*Cornwallis, C. K. \& Birkhead, T. R. (2006). Social status and availability of females determine patterns of sperm allocation in the fowl. Evolution 60, 1486-1493.

*Cornwallis, C. K. \& Birkhead, T. R. (2007). Changes in sperm quality and numbers in response to experimental manipulation of male social status and female attractiveness. American Naturalist 170, 758-770.

Cornwallis, C. K. \& O'Connor, E. A. (2009). Sperm: seminal fluid interactions and the adjustment of sperm quality in relation to female attractiveness. Proceedings of the Royal Society of London Series B-Biological Sciences 276, 3467-3475.

Côté, I., Curtis, P., Rothstein, H. \& Stewart, G. (2011). Gathering data: searching the literature and selection criteria. In Handbook of Meta-analysis in Ecology and Evolution (eds J. Koricheva, J. Gurevitch, K. Mengersen), Princeton University Press, Princeton.

Crean, A.J., Marshall, D.J. (2008). Gamete plasticity in a broadcast spawning marine invertebrate. Proceedings of the National Academy of Sciences USA 105, $13508-13513$.

Curtis, P., Mengersen, K., Lajeunesse, M., Rothstein, H. R. \& Stewart, G. (2011). Extraction and critical appraisal of data for meta-analysis. In Handbook of Metaanalysis in Ecology and Evolution (eds J. Koricheva, J. Gurevitch, K. Mengersen), Princeton University Press, Princeton. (in press).

*Danielson-francois, A. M. \& Bukowski, T. (2005). Female mating history influences copulation behavior but not sperm release in the orb-weaving spider Tetragnatha versicolor (Araneae, Tetragnathidae). Fournal of Insect Behavior 18, 131-148.

*Delbarco-Trillo, J. \& Ferkin, M. H. (2004). Male mammals respond to a risk of sperm competition conveyed by odours of conspecific males. Nature 431, 446-449.

*Delbarco-Trillo, J. \& Ferkin, M. H. (2006). Male meadow voles respond differently to risk and intensity of sperm competition. Behavioral Ecology 17, 581-585.

Delbarco-Trillo, J. \& Ferkin, M. H. (2007). Risk of sperm competition does not influence copulatory behavior in the promiscuous meadow vole (Microtus pennsylvanicus). Fournal of Ethology 25, 139-145.

Dewsbury, D. A. (1981). Effects of novelty on copulatory-behavior - the Coolidge effect and related phenomena. Psychological Bulletin 89, 464-482.
Dewsbury, D. A. (1982). Ejaculate cost and male choice. American Naturalist 119, $601-610$.

Díaz-Uriarte, R. \& Garland Jr., T. (1998). Effects of branch length errors on the performance of phylogenetically independent contrasts. Systematic Biology 47, 654-672.

*Droney, D. G. \& Thaker, M. (2006). Factors influencing mating duration and male choice in the red milkweed beetle, Tetraopes tetrophthalmus (Forster) (Coleoptera: Cerambycidae). Ethology Ecology \& Evolution 18, 173-183.

*Dunn, A. M., Andrews, T., Ingrey, H., Riley, J. \& Wedell, N. (2006). Strategic sperm allocation under parasitic sex-ratio distortion. Biology Letters 2, 78-80.

Duval, S. \& Tweedie, R. (2000a). A nonparametric "trim and fill" method of accounting for publication bias in meta-analysis. Fournal of the American Statistical Association 95, 89-98.

Duval, S. \& Tweedie, R. (2000b). Trim and fill: A simple funnel-plot-based method of testing and adjusting for publication bias in meta-analysis. Biometrics 56, 455-463.

*Elgar, M. A., Champion DE Crespigny, F.E. \& Ramamurthy, S. (2003). Male copulation behaviour and the risk of sperm competition. Animal Behaviour 66, $211-216$.

EngQvist, L. \& Reinhold, K. (2005). Pitfalls in experiments testing predictions from sperm competition theory. Fournal of Evolutionary Biology 18, 116-123.

EngQvist, L. \& Reinhold, K. (2006). Theoretical influence of female mating status and remating propensity on male sperm allocation patterns. Fournal of Evolutionary Biology 19, 1448-1458.

*EngQvist, L. \& SAuer, K. P. (2003). Determinants of sperm transfer in the scorpionfly Panorpa cognata: Male variation, female condition and copulation duration. Journal of Evolutionary Biology 16, 1196-1204.

Evans, J. P. (2009). No evidence for sperm priming responses under varying sperm competition risk or intensity in guppies. Naturwissenschaften $\mathbf{9 6}$, 771-779.

*Evans, J. P., Pierotti, M. \& Pilastro, A. (2003). Male mating behavior and ejaculate expenditure under sperm competition risk in the eastern mosquitofish. Behavioral Ecology 14, 268-273.

*Farmer, D. C. \& Barnard, C. J. (2000). Fluctuating asymmetry and sperm transfer in male decorated field crickets (Gryllodes sigillatus). Behavioral Ecology and Sociobiology 47, 287-292.

*FitzPatrick, J. L. \& Liley, N. R. (2008). Ejaculate expenditure and timing of gamete release in rainbow trout Oncorhynchus mykiss. Fournal of Fish Biology 73, $262-274$.

*Friberg, U. (2006). Male perception of female mating status: Its effect on copulation duration, sperm defence and female fitness. Animal Behaviour 72, 1259-1268.

*Fritz, A. H. (2004). Sperm storage patterns in singly mated females of the caribbean fruit fly, Anastrepha suspensa (Diptera: Tephritidae). Annals of the Entomological Society of America 97, 1328-1335.

Fromhage, L., Mcnamara, J. M. \& Houston, A. I. (2008). Sperm allocation strategies and female resistance: A unifying perspective. American Naturalist 172, 25-33.

*Fuller, R. C. (1998). Sperm competition affects male behaviour and sperm output in the rainbow darter. Proceedings of the Royal Society of London Series B-Biological Sciences 265, 2365-2371.

*GaGe, A. R. \& Barnard, C. J. (1996). Male crickets increase sperm number in relation to competition and female size. Behavioral Ecology and Sociobiology 38, 349-353.

*GAGE, M. J. G. (1991). Risk of sperm competition directly affects ejaculate size in the Mediterranean fruit-fly. Animal Behaviour 42, 1036-1037.

GAGE, M. J. G. (1995). Continuous variation in reproductive strategy as an adaptive response to population-density in the moth Plodia interpunctella. Proceedings of the Royal Society of London Series B-Biological Sciences 261, 25-30.

*GAGE, M. J. G. (1998). Influences of sex, size, and symmetry on ejaculate expenditure in a moth. Behavioral Ecology 9, 592-597.

*GAGE, M.J. G. \& BAKER, R. R. (1991). Ejaculate size varies with sociosexual situation in an insect. Ecological Entomology 16, 331-337.

Gage, M. J. G., Stockley, P. \& Parker, G. A. (1995). Effects of alternative male mating strategies on characteristics of sperm production in the Atlantic salmon (Salmo salar): Theoretical and empirical investigations. Philosophical Transactions of the Royal Society of London Series B-Biological Sciences 350, 391-399.

*Galeotti, P., Pupin, F., Rubolini, D., Sacchi, R., Nardi, P. A. \& Fasola, M. (2007). Effects of female mating status on copulation behaviour and sperm expenditure in the freshwater crayfish Austropotamobius italicus. Behavioral Ecology and Sociobiology 61, 711-718.

*Galeotti, P., Rubolini, D., Pupin, F., Sacchi, R., Altobelli, E., Nardi, P. A. \& Fasola, M. (2009). Presence of rivals reduces mating probability but does not affect ejaculate size in the freshwater crayfish Austropotamobius italicus. Behaviour 146, $45-68$.

*GAO, Y. \& KANG, L. (2006). Operational sex ratio and alternative reproductive behaviours in Chinese bushcricket, Gampsocleis gratiosa. Ethology 112, 325-331.

*Garcia-Gonzalez, F. \& Gomendio, M. (2004). Adjustment of copula duration and ejaculate size according to the risk of sperm competition in the golden egg bug (Phyllomorpha laciniata). Behavioral Ecology 15, 23-30. 
Gatesy, J., Baker, R.H. \& HAyAshi, C. (2004). Inconsistencies in arguments for the supertree approach: supermatrices versus supertrees of Crocodylia. Systematic Biology $53,342-355$.

Gay, L., Hosken, D. J., Vasudev, R., Tregenza, T. \& Eady, P. E. (2009). Sperm competition and maternal effects differentially influence testis and sperm size in Callosobruchus maculatus. Fournal of Evolutionary Biology 22, 1143-1150.

Gershman, S. N. \& SaKaluk, S. K. (2009). No Coolidge effect in decorated crickets. Ethology 115, 774-780

Gillingham, M. A. F., Richardson, D. S., Lovlie, H., Moynihan, A., WorLEY, K. \& Pizzari, T. (2009). Cryptic preference for MHC-dissimilar females in male red junglefowl, Gallus gallus. Proceedings of the Royal Society of London Series B-Biological Sciences 276, 1083-1092.

Griffith, S. C., Owens, I. P. F. \& Thuman, K. A. (2002). Extra pair paternity in birds: a review of interspecific variation and adaptive function. Molecular Ecology 11, 2195-2212.

Guevara-Fiore, P., Skinner, A. \& Watt, P. J. (2009). Do male guppies distinguish virgin females from recently mated ones? Animal Behaviour 77, 425-431.

Hadfield, J.D. \& Nakagawa, S. (2010). General quantitative genetic methods for comparative biology: phylogenies, taxonomies and multi-trait models for continuous and categorical characters. Fournal of Evolutionary Biology 23, 494-508.

Haederer, I. K., Werminghausen, J., Michiels, N. K., Timmermeyer, N. \& ANTHEs, N. (2009). No effect of mate novelty on sexual motivation in the freshwater snail Biomphalaria glabrata. Frontiers in Zoology 6.

Härdling, R., Gosden, T. \& Aguilee, R. (2008). Male mating constraints affect mutual mate choice: Prudent male courting and sperm-limited females. American Naturalist 172, 259-271.

Harris, W. E. \& Moore, P.J. (2005). Sperm competition and male ejaculate investment in Nauphoeta cinerea: effects of social environment during development. Journal of Evolutionary Biology 18, 474-480.

*He, Y. \& Miyata, T. (1997). Variations in sperm number in relation to larval crowding and spermatophore size in the armyworm, Pseudaletia separata. Ecological Entomology 22, 41-46.

Hedges, L. V. \& Olkin, I. (1985). Statistical Methods for Meta-Analysis. Academic Press, San Diego.

*Holwell, G. I. (2007). Spermatophore feeding and mating behaviour in praying mantids (Mantodea: Liturgusidae). Journal of Zoology 271, 255-260.

Immler, S., Pryke, S.R., Birkhead, T.R., Griffith, S.C. (2010). Pronounced within-individual plasticity in sperm morphology across social environments. Evolution 64, 1634-1643.

JANICKE, T. \& SCHÄRER, L. (2009). Determinants of mating and sperm-transfer success in a simultaneous hermaphrodite. Journal of Evolutionary Biology 22, 405-415.

Jennions, M. D., Lortie, C. \& Koricheva, J. (2011a). Meta-analysis and interpreting the scientific literature. In Handbook of Meta-analysis in Ecology and Evolution (eds J. Koricheva, J. Gurevitch, K. Mengersen), Princeton University Press, Princeton. (in press)

Jennions M. D., Lortie, C., Koricheva, J. (2011b). Meta-analysis for evaluation of controversies and theory. In Handbook of Meta-analysis in Ecology and Evolution (eds J. Koricheva, J. Gurevitch, K. Mengersen), Princeton University Press, Princeton. (in press)

Jennions, M. D., Lortie, C., Rosenberg, M. \& Rothstein, H. (2011c). Publication and related biases. In Handbook of Meta-analysis in Ecology and Evolution (eds J. Koricheva, J. Gurevitch, K. Mengersen), Princeton University Press, Princeton. (in press)

Jennions, M. D. \& Moller, A. P. (2002). Relationships fade with time: a metaanalysis of temporal trends in publication in ecology and evolution. Proceedings of the Royal Society of London Series B-Biological Sciences 269, 43-48.

Jennions, M. D., Moller, A. P. \& Petrie, M. (2001). Sexually selected traits and adult survival: A meta-analysis. Quarterly Review of Biology 76, 3-36.

Jennions, M. D. \& Petrie, M. (2000). Why do females mate multiply? A review of the genetic benefits. Biological Reviews 75, 21-64.

* Jivoff, P. (1997). Sexual competition among male blue crab, Callinectes sapidus. Biological Bulletin 193, 368-380

Jones, T. M. \& Elgar, M. A. (2008). Male insemination decisions and sperm quality influence paternity in the golden orb-weaving spider. Behavioral Ecology 19, 285-291.

*Jones, T. M., Featherston, R., Paris, D. B. B. P. \& Elgar, M. A. (2007). Agerelated sperm transfer and sperm competitive ability in the male hide beetle. Behavioral Ecology 18, 251-258.

Kekäläinen, J., Vallunen, J.A., Primmer, C.R., Rättyä, J., Taskinen J. (2009). Signals of major histocompatability overdominance in a wild salmonoid population. Proceedings of the Royal Society of London Series B-Biological Sciences 276, 3133-3140.

KeLly, C.D. (2006). Replicating empirical research in behavioral ecology: How and why it should be done but rarely ever is. Quarterly Review of Biology 81, 221-236

Kilgallon, S. J. \& Simmons, L. W. (2005). Image content influences men's semen quality. Biology Letters 1, 253-255.

KoEnE, J. M. \& TER MAAT, A. (2007). Coolidge effect in pond snails: male motivation in a simultaneous hermaphrodite. BMC Evolutionary Biology 7.

Kокко, H. \& Jennions, M. D. (2008). Parental investment, sexual selection and sex ratios. Fournal of Evolutionary Biology 21, 919-948.
Kокко, H. \& Oтs, I. (2006). When not to avoid inbreeding. Evolution 60, 467-475. Koricheva, J. (2003). Non-significant results in ecology: a burden or a blessing in disguise? Oikos 102, 397-401.

Koricheva, J. \& GUREvitch, J. (2011). Types of quantitative research synthesis and history of meta-analysis in ecology. In Handbook of Meta-analysis in Ecology and Evolution (eds J. Koricheva, J. Gurevitch, K. Mengersen), Princeton University Press, Princeton. (in press)

Koricheva, J. Gurevitch, J. \& Mengersen, K. (eds.) (2011). Handbook of Meta analysis in Ecology and Evolution. Princeton University Press, Princeton. (in press)

Lajeunesse, M. J. (2009). Meta-analysis and the comparative phylogenetic method. American Naturalist 174, 369-381

Larsdotter-Mellstrom, H. \& Wiklund, C. (2009). Males use sex pheromone assessment to tailor ejaculates to risk of sperm competition in a butterfly. Behavioral Ecology 20, 1147-1151.

Leimu, R. \& Koricheva, J. (2005). What determines the citation frequency of ecological papers? Trends in Ecology \& Evolution 20, 28-32.

Levitan, D. R. (2010). Sexual selection in external fertilizers. In Evolutionary Behavioral Ecology (eds D. F. Westneat, C. W. Fox), pp 365-378, Oxford University Press, Oxford.

*Lewis, Z. \& Wedell, N. (2007). Effect of adult feeding on male mating behaviour in the butterfly, Bicyclus anynana (Lepidoptera: Nymphalidae). Fournal of Insect Behavior 20, 201-213.

LEwis, Z. \& WedELL, N. (2009). Male moths reduce sperm investment in relatives. Animal Behaviour 77, 1547-1550.

Linder, H.P., Hardy, C.R. \& Rutschmann, F. (2005). Taxon sampling effects in molecular clock dating: an example from the African Restionaceae. Molecular Phylogenetics \& Evolution 35, 569-582.

*Linley, J. \& Hinds, M. (1975). Quantity of male ejaculate influenced by female unreceptivity in fly, Culicoides melleus. Fournal of Insect Physiology 21, 281-285.

Loose, M. J. \& Koene, J. M. (2008). Sperm transfer is affected by mating history in the simultaneously hermaphroditic snail Lymnaea stagnalis. Invertebrate Biology 127 $162-167$.

Lyons, G. \& Barnard, C. J. (2006). A learned response to sperm competition in the field cricket, Gryllus bimaculatus (de Geer). Animal Behaviour 72, 673-680.

*Macdiarmid, A. B. \& Butler, M. J. (1999). Sperm economy and limitation in spiny lobsters. Behavioral Ecology and Sociobiology 46, 14-24.

*Mallard, S. T. \& Barnard, C. J. (2003). Competition, fluctuating asymmetry and sperm transfer in male gryllid crickets (Gryllus bimaculatus and Gryllodes sigillatus). Behavioral Ecology and Sociobiology 53, 190-197.

Marconato, A. \& Shapiro, D. Y. (1996). Sperm allocation, sperm production and fertilization rates in the bucktooth parrotfish. Animal Behaviour 52, 971-980.

Marconato, A., Tessari, V. \& Marin, G. (1995). The mating system of Xyrichthys novacula - sperm economy and fertilization success. Fournal of Fish Biology 47, 292-301.

*Martin, O. Y. \& Hosken, D. J. (2002). Strategic ejaculation in the common dung fly Sepsis cynipsea. Animal Behaviour 63, 541-546.

Mcgraw, L. A., Fiumera, A. C., Ramakrishnan, M., Madhavarapu, S., Clark A. G. \& Wolfner, M. F. (2007). Larval rearing environment affects several postcopulatory traits in Drosophila melanogaster. Biology Letters 3, 607-610.

Mcnamara, K. B., Elgar, M. A. \& Jones, T. M. (2010). Adult responses to larval population size in the almond moth, Cadra cautella. Ethology 116, 39-46.

*Mcnamara, K. B., Jones, T. M. \& Elgar, M. A. (2004). Female reproductive status and mate choice in the hide beetle, Dermestes maculatus. Fournal of Insect Behavior $\mathbf{1 7}$ 337-352.

Milinski, M. (2006). The major histocompatibility complex, sexual selection, and mate choice. Annual Review of Ecology Evolution and Systematics 37, 159-186.

Moher, D., Tsertsvadze, A., Tricco, A. C., Eccles, M., Grimshaw, J., SampSON, M. \& Barrowman, N. (2008). When and how to update systematic reviews. Cochrane Database of Systematic Reviewes 1.

MøLler, A. P. \& Jennions, M. D. (2001a). How important are direct fitness benefits of sexual selection? Naturwissenschaften 88, 401-415.

MøLleR, A. P. \& Jennions, M. D. (2001b). Testing and adjusting for publication bias. Trends in Ecology \& Evolution 16, 580-586.

Møller, A. P. \& Jennions, M. D. (2002). How much variance can be explained by ecologists and evolutionary biologists? Oecologia $132,492-500$.

Møller, A. P., Thornhill, R. \& Gangestad, S. W. (2005). Direct and indirect tests for publication bias: asymmetry and sexual selection. Animal Behaviour 70, 497-506.

Murtaugh, P. A. (2002). Journal quality, effect size, and publication bias in metaanalysis. Ecology 83, 1162-1166.

Nakatsuru, K. \& Kramer, D. L. (1982). Is sperm cheap? Limited male-fertility and female choice in the lemon tetra (Pisces, Characidae). Science 216, 753-755.

*Nicholls, E. H., Burke, T. \& Birkhead, T. R. (2001). Ejaculate allocation by male sand martins, Riparia riparia. Proceedings of the Royal Society of London Series B-Biological Sciences 268, 1265-1270.

*Olsson, M. (2001). 'Voyeurism' prolongs copulation in the dragon lizard Ctenophorus fordi. Behavioral Ecology and Sociobiology 50, 378-381.

Olsson, M., Madsen, T. \& Shine, R. (1997). Is sperm really so cheap? Costs of reproduction in male adders, Vipera berus. Proceedings of the Royal Society of London Series B-Biological Sciences 264, 455-459. 
*Oppliger, A., Hosken, D.J. \& Ribi, G. (1998). Snail sperm production characteristics vary with sperm competition risk. Proceedings of the Royal Society of London Series B-Biological Sciences 265, 1527-1534.

PARker, G.A. (1970). Sperm competition and its evolutionary consequences in the insects. Biological Reviewes 45, 525-568.

PARker, G. A. (1998). Sperm competition and the evolution of ejaculates: towards a theory base. In Sperm Competition and Sexual Selection (eds T. R. BIRKHEAD, A. P. M $\varnothing$ LLER), pp. 3-54, Academic University Press, New York.

Parker, G. A. (2006). Sexual conflict over mating and fertilization: an overview. Philosophical Transactions of the Royal Society B-Biological Sciences 361, 235-259.

Parker, G. A. \& Ball, M. A. (2005). Sperm competition, mating rate and the evolution of testis and ejaculate sizes: a population model. Biology Letters 1, 235-238.

Parker, G. A., Ball, M. A., Stockley, P. \& Gage, M. J. G. (1996). Sperm competition games: Individual assessment of sperm competition intensity by group spawners. Proceedings of the Royal Society of London Series B-Biological Sciences 263 $1291-1297$

Parker, G. A., Ball, M. A., Stockley, P. \& Gage, M. J. G. (1997). Sperm competition games: a prospective analysis of risk assessment. Proceedings of the Royal Society of London Series B-Biological Sciences 264, 1793-1802.

Parker, G.A. \& Pizzari, T. (2010). Sperm competition and ejaculate economics. Biological Reviewes 85, 897-934.

*Parker, G., Simmons, L. \& WARd, P. (1993). Optimal copula duration in dungflies: Effects of frequency-dependence and female mating status. Behavioral Ecology and Sociobiology 32, 157-166.

*Pilastro, A., Scaggiante, M. \& Rasotto, M.B. (2002). Individual adjustment of sperm expenditure accords with sperm competition theory. Proceedings of the National Academy of Sciences USA 99, 9913-9915.

Pitnick, S., Hosken, D. J. \& Birkhead, T. R. (2009a). Sperm morphological diversity. In Sperm Biology: an evolutionary perspective (eds T. R. BIRKHEAD, D. J. Hosken, S. Pitnick), pp. 69-149, Academic Press, New York.

Pitnick, S. \& Markow, T. A. (1994). Male gametic strategies - sperm size, testes size, and the allocation of ejaculate among successive mates by the sperm-limited fly Drosophila pachea and its relatives. American Naturalist 143, 785-819.

Pitnick, S., Wolfner, M. F. \& Suarez, S. S. (2009b). Ejaculate-female and spermfemale interactions. In Sperm Biology: an evolutionary perspective (eds T. R. BIRKHEAD, D. J. Hosken, S. Pitnick), pp. 247-304, Academic Press, New York.

Pizzari, T. (2002). Sperm allocation, the Coolidge effect and female polyandry. Trends in Ecology E Evolution 17, 456-456.

Pizzari, T. (2009). Sexual selection: sperm in the fast lane. Current Biology 19, R292-R294.

*Pizzari, T., Cornwallis, C. K., Lovlie, H., Jakobsson, S. \& Birkhead, T. R. (2003). Sophisticated sperm allocation in male fowl. Nature 426, 70-74.

Pizzari, T., Lovlie, H. \& Cornwallis, C. K. (2004). Sex-specific, counteracting responses to inbreeding in a bird. Proceedings of the Royal Society of London Series B-Biological Sciences 271, 2115-2121.

Pizzari, T. \& Parker, G. A. (2009). Sperm competition and sperm phenotype. In Sperm Biology: an evolutionary perspective (eds T. R. BirkheAd, D.J. HoskeN, S. Pitnick), pp. 207-245, Academic Press, New York

Poinni, A. (2006). Complexity of seminal fluid: a review. Behavioral Ecology and Sociobiology 60, 289-310

*Pound, N. \& Gage, M. J. G. (2004). Prudent sperm allocation in Norway rats, Rattus norvegicus: a mammalian model of adaptive ejaculate adjustment. Animal Behaviour 68 , 819-823.

Pullin, A. S. \& Stewart, G. B. (2006). Guidelines for systematic review in conservation and environmental management. Conservation Biology 20, 1647-1656.

*Putz, A., Michiels, N. K. \& Anthes, N. (2008). Mating behaviour of the sperm trading sea slug Chelidonura hirundinina: Repeated sex role alternation balances reciprocity. Ethology 114, 85-94.

R DEVELOPMENT CORE TEAM (2008). R: A language and environment for statistical computing. Version 2.8.0.R Foundation for Statistical Computing, Vienna, Austria.

*Radtke, M. G. \& Rutowski, R. L. (2002). Variation in the number of sperm transferred during mating among males of the Colorado potato beetle (Coleoptera: Chrysomelidae). Fournal of Insect Physiology 48, 1087-1092.

*RAmm, S. A. \& Stockley, P. (2007). Ejaculate allocation under varying sperm competition risk in the house mouse, Mus musculus domesticus. Behavioral Ecology 18, $491-495$.

*Reinhardt, K. (2001). Determinants of ejaculate size in a grasshopper (Chorthippus parallelus). Behavioral Ecology and Sociobiology 50, 503-510.

*Reinhardt, K. \& ARLt, D. (2003). Ejaculate size variation in the migratory locust, Locusta migratoria. Behaviour 140, 319-332.

Reinhold, K., Kurtz, J. \& EngQvist, L. (2002). Cryptic male choice: sperm allocation strategies when female quality varies. Foumal of Evolutionary Biology 15, 201-209.

Roberts, J. D. \& Byrne, P. G. (2010). Evolutionary causes and consequences of polyandry and sperm competition in anuran amphibians. Advances in the Study of Behaviour (in press).

Robinson, D. M., Aspbury, A. S. \& Gabor, C. R. (2008). Differential sperm expenditure by male sailfin mollies, Poecilia latipinna, in a unisexual-bisexual species complex and the influence of spermiation during mating. Behavioral Ecology and Sociobiology 62, 705-711.

Rosenberg, M. S. (2005). The file-drawer problem revisited: A general weighted method for calculating fail-safe numbers in meta-analysis. Evolution 59, 464-468.

Rosenberg, M. S., Adams, D. C. \& Gurevitch, J. (2000). MetaWin Version 2.0: Statistical Software for Meta-Analysis. Sinauer Associates, Massachusetts.

Rothstein, H. R., Sutton, A. J. \& Borenstein M. (2009). Publication Bias in MetaAnalysis. John Wiley and Sons, New York.

*Rubolini, D., Galeotti, P., Ferrari, G., Spairani, M., Bernini, F. \& Fasola, M. (2006). Sperm allocation in relation to male traits, female size, and copulation behaviour in a freshwater crayfish species. Behavioral Ecology and Sociobiology 60, 212-219.

*Sakaluk, S. K. \& Muller, J. K. (2008). Risk of sperm competition mediates copulation duration, but not paternity, of male burying beetles. Fournal of Insect Behavior 21, 153-163.

*Sato, T., Ashidate, M., Jinbo, T. \& Goshima, S. (2006). Variation of sperm allocation with male size and recovery rate of sperm. Marine Ecology Progress Series 312, 189-199.

*Sato, T. \& Goshima, S. (2007a). Effects of risk of sperm competition, female size, and male size on number of ejaculated sperm in the stone crab Hapalogaster dentata. Fournal of Crustacean Biology 27, 570-575.

*SAto, T. \& Goshima, S. (2007b). Sperm allocation in response to a temporal gradient in female reproductive quality in the stone crab, Hapalogaster dentata. Animal Behaviour 74, 903-910.

*Scaggiante, M., Rasotto, M. B., Romualdi, C. \& Pilastro, A. (2005). Territorial male gobies respond aggressively to sneakers but do not adjust their sperm expenditure. Behavioral Ecology 16, 1001-1007.

*Schaefer, M. A., Misof, B. \& UhL, G. (2008). Effects of body size of both sexes and female mating history on male mating behaviour and paternity success in a spider. Animal Behaviour 76, 75-86.

SCHÄRER, L. (2009). Tests of sex allocation theory in simultaneously hermaphroditic animals. Evolution 63, 1377-1405.

Schärer, L. \& LAdurner, P. (2003). Phenotypically plastic adjustment of sex allocation in a simultaneous hermaphrodite. Proceedings of the Royal Society of London Series B-Biological Sciences 270, 935-941.

*Schaus, J. M. \& Sakaluk, S. K. (2001). Ejaculate expenditures of male crickets in response to varying risk and intensity of sperm competition: Not all species play games. Behavioral Ecology 12, 740-745.

Schlupp, I. \& Plath, M. (2005). Male mate choice and sperm allocation in a sexual/asexual mating complex of Poecilia (Poeciliidae, Teleostei). Biology Letters 1, $169-171$.

*Schneider, J. M., Fromhage, L. \& Uhl, G. (2005). Copulation patterns in the golden orb-web spider Nephila madagascariensis. Fournal of Ethology 23, 51-55.

Schofl, G. \& TAвorsky, M. (2002). Prolonged tandem formation in firebugs (Pyrrhocoris apterus) serves mate-guarding. Behavioral Ecology and Sociobiology 52, $426-433$

Schwarzer, G. (2009). meta: Meta-Analysis with R, R package, version 0.9-18.

Shapiro, D. Y., Marconato, A. \& Yoshikawa, T. (1994). Sperm economy in a coral-reef fish, Thalassemia bifasciatum. Ecology 75, 1334-1344.

*Sevgili, H. \& Reinhold, K. (2007). No evidence for strategic male mating effort in response to female weight in a bushcricket. Behaviour 144, 1179-1192.

Simmons, L. W. (2001). Sperm Competition and its Evolutionary Consequences in the Insects. Princeton University Press, Princeton.

*Simmons, L., Craig, M., Llorens, T., Schinzig, M. \& Hosken, D. (1993). Bushcricket spermatophores vary in accord with sperm competition and parental investment theory. Proceedings of the Royal Society of London Series B-Biological Sciences 251, $183-186$.

*Simmons, L. W. \& Kvarnemo, C. (1997). Ejaculate expenditure by male bushcrickets decreases with sperm competition intensity. Proceedings of the Royal Society of London Series B-Biological Sciences 264, 1203-1208.

*Singh, S. R. \& Singh, B. N. (2004). Female remating in Drosophila: Comparison of duration of copulation between first and second matings in six species. Current Science 86, $465-470$.

*Siva-Jothy, M. T. \& StutT, A. D. (2003). A matter of taste: Direct detection of female mating status in the bedbug. Proceedings of the Royal Society of London Series B-Biological Sciences 270, 649-652.

*Smith, C., Pateman-Jones, C., Zieba, G., Przybylski, M. \& Reichard, M. (2009). Sperm depletion as a consequence of increased sperm competition risk in the European bitterling, Rhodeus amarus. Animal Behaviour 77, 1227-1233.

*SNook, R. R. (1998). The risk of sperm competition and the evolution of sperm heteromorphism. Animal Behaviour 56, 1497-1507.

SNOOK, R. R. (2005). Sperm in competition: not playing by the numbers. Trends in Ecology \& Evolution 20, 46-53.

Steiger, S., Franz, R., Eggert, A. K. \& Muller, J. K. (2008). The Coolidge effect, individual recognition and selection for distinctive cuticular signatures in a burying beetle. Proceedings of the Royal Society of London Series B-Biological Sciences 275, 1831-1838.

Stewart, G., Cote, I., Rothstein, H., Curtis, P. \& Pullin, A. (2011). Defining the problem and developing a protocol. In Handbook of Meta-analysis in Ecology and 
Evolution (eds J. Koricheva, J. Gurevitch, K. Mengersen), Princeton University Press, Princeton. (in press)

Stockley, P. (1999). Sperm selection and genetic incompatibility: does relatedness of mates affect male success in sperm competition? Proceedings of the Royal Society of London Series B-Biological Sciences 266, 1663-1669.

Stockley, P. \& SeAl, N. J. (2001). Plasticity in reproductive effort of male dung flies (Scatophaga stercoraria) as a response to larval density. Functional Ecology 15, 96-102.

SUTER, R.B. (1990). Courtship and the assessment of virginity by male bowl and doily spiders. Animal Behaviour 39, 307-313.

TAвоRsky, M. (1998). Sperm competition in fish: 'bourgeois' males and parasitic spawning. Trends in Ecology \& Evolution 13, 222-227.

*Taylor, P. W., Kaspi, R., Mossinson, S. \& Yuval, B. (2001). Age-dependent insemination success of sterile mediterranean fruit flies. Entomologia Experimentalis et Applicata 98, 27-33.

*Taylor, P. W., Kaspi, R. \& Yuval, B. (2000). Copula duration and sperm storage in mediterranean fruit flies from a wild population. Physiological Entomology 25, 94-99.

Tazzyman, S. J., Pizzari, T., Seymour, R. M. \& Pomiankowski, A. (2009). The evolution of continuous variation in ejaculate expenditure strategy. American Naturalist 174, E71-E82.

Teng, Z. Q. \& Zhang, Q. W. (2009). Determinants of male ejaculate investment in the cotton bollworm Helicoverpa armigera: mating history, female body size and male age. Physiological Entomology 34, 338-344.

*Thomas, M. L. \& Simmons, L. W. (2007). Male crickets adjust the viability of their sperm in response to female mating status. American Naturalist 170, 190-195.

Thomas, M. L. \& Simmons, L. W. (2009). Male-derived cuticular hydrocarbons signal sperm competition intensity and affect ejaculate expenditure in crickets. Proceedings of the Royal Society of London Series B-Biological Sciences 276, 383-388.

*Uhia, E. \& Rivera, A. C. (2005). Male damselflies detect female mating status: Importance for postcopulatory sexual selection. Animal Behaviour 69, 797-804.

Vaughn, A. A., Delbarco-Trillo, J. \& Ferkin, M. H. (2008). Sperm investment in male meadow voles is affected by the condition of the nearby male conspecifics. Behavioral Ecology 19, 1159-1164.

*Velando, A., Eiroa, J. \& Dominguez, J. (2008). Brainless but not clueless: Earthworms boost their ejaculates when they detect fecund non-virgin partners. Proceedings of the Royal Society of London Series B-Biological Sciences 275, 1067-1072.

Wang, O. \& Millar, J. G. (1997). Reproductive behavior of Thyanta pallidovirens (Heteroptera: Pentatomidae). Annals of the Entomological Society of America 90, 380-388.

*Wedell, N. (1992). Protandry and mate assessment in the wartbiter Decticus verrucivorus (Orthoptera, Tettigoniidae). Behavioral Ecology and Sociobiology 31, 301-308.

*Wedell, N. (1998). Sperm protection and mate assessment in the bushcricket Coptaspis sp. 2. Animal Behaviour 56, 357-363.

*Wedell, N. \& Cook, P. A. (1999a). Butterflies tailor their ejaculate in response to sperm competition risk and intensity. Proceedings of the Royal Society of London Series B-Biological Sciences 266, 1033-1039.

Wedell, N. \& Cook, P. A. (1999b). Strategic sperm allocation in the Small White butterfly Pieris rapae (Lepidoptera: Pieridae). Functional Ecology 13, 85-93.

Wedell, N., Gage, M. J. G. \& Parker, G. A. (2002). Sperm competition, male prudence and sperm-limited females. Trends in Ecology \& Evolution 17, 313-320.

WiEns, J.J. (2003). Missing data, incomplete taxa, and phylogenetic accuracy. Systematic Biology 52, 528-538.

Williams, P. D., Day, T. \& Cameron, E. (2005). The evolution of sperm-allocation strategies and the degree of sperm competition. Evolution 59, 492-499.
*XU, J. \& WANG, O. (2009). Male moths undertake both pre- and in-copulation mate choice based on female age and weight. Behavioral Ecology and Sociobiology 63, 801-808.

Yamane, T. \& Miyatake, T. (2008). Strategic ejaculation and level of polyandry in Callosobruchus chinensis (Coleoptera : Bruchidae). Fournal of Ethology 26, 225-231.

*Yasui, Y. (1994). Adaptive-control of copulation duration by males under sperm competition in the mite, Macrocheles muscaedomesticae. Experimental \& Applied Acarology 18, 543-554.

*Yusa, Y. (1994). Factors regulating sperm transfer in an hermaphroditic sea hare, Aplysia parvula morch, 1863 (Gastropoda, Opisthobranchia). Fournal of Experimental Marine Biology and Ecology 181, 213-221.

Zahradnik, T. D., Lemay, M. A. \& Boulding, E. G. (2008). Choosy males in a littorinid gastropod: male Littorina subrotundata prefer large and virgin females. Fournal f Molluscan Studies 74, 245-251.

*Zbinden, M., Mazzi, D., Kunzler, R., Largiader, C. R. \& Bakker, T. C. M. 2003). Courting virtual rivals increase ejaculate size in sticklebacks (Gasterosteus aculeatus). Behavioral Ecology and Sociobiology 54, 205-209.

\section{SUPPORTING INFORMATION}

Additional supporting information may be found in the online version of this article.

Appendix 1. Effect sizes (Hedges' $d$ ) for the presence of rival males on measures of male ejaculate expenditure when one rival male (65 samples, 35 species, 37 studies) or many rival males (20 samples, 16 species, 13 studies) are present.

Appendix 2. Effect sizes (Hedges' $d$ ) between female mating status and measure of male ejaculate expenditure for 72 samples from 40 species in 29 studies.

Appendix 3. Effect size (Pearson's $r$ ) between female quality and meaure of male ejaculate expenditure for 93 samples from 40 species in 46 studies.

Reference database An .xml file for use with bibliographic reference software.

Please note: Wiley-Blackwell are not responsible for the content or functionality of any supporting materials supplied by the authors. Any queries (other than missing material) should be directed to the corresponding author for the article.

(Received 15 July 2010; revised 14 February 2011; accepted 22 February 2011; published online 17 March 2011) 